\title{
Behaviour of TiC Particles on the Co50-Based Coatings by Laser Cladding: Morphological Characteristics and Growth Mechanism
}

\author{
Nga Thi-Hong Pham (iD) and Van-Thuc Nguyen (i) \\ Mechanical Engineering Faculty, HCMC University of Technology and Education, 1 Vo Van Ngan St., Thu Duc District, \\ Ho Chi Minh City 700000, Vietnam \\ Correspondence should be addressed to Van-Thuc Nguyen; nguyenvanthuc1510@gmail.com
}

Received 10 March 2020; Revised 22 April 2020; Accepted 7 May 2020; Published 28 May 2020

Academic Editor: Francisco Javier Fernández Fernández

Copyright (c) 2020 Nga Thi-Hong Pham and Van-Thuc Nguyen. This is an open access article distributed under the Creative Commons Attribution License, which permits unrestricted use, distribution, and reproduction in any medium, provided the original work is properly cited.

\begin{abstract}
H13 steel surfaces are covered by coatings of Co-based alloy with $0,10,20$, and $30 \mathrm{wt}$. \% TiC using the laser cladding (LC) method. The morphological characteristics, growth mechanism, and the mechanical properties of TiC on the microstructure of the coatings were studied. The results show that $\mathrm{TiC}$ in the $\mathrm{TiC} / \mathrm{Co} 50$ composite coating is composed of two parts: incompletely melted TiC and in situ TiC. TiC content has a great effect on the morphology of $\mathrm{TiC}$, and it exists in different shapes: original TiC, fine-particle TiC, segregated TiC, petal-shaped TiC, and branch-shaped TiC. Additionally, the morphology of TiC in different areas of the coating is different, while $\mathrm{TiC}$ size gradually increases from bonding zone to surface. In the $10 \% \mathrm{TiC}+\mathrm{Co} 50$ coating, TiC mainly appears as undermelted, fine particles, precipitates, and having shapes of polygons and petals. From the bottom of this coating, the number of petal-shaped $\mathrm{TiC}$ has increased, and the particle size is also enlarged. In the $20 \% \mathrm{TiC}+\mathrm{Co} 50$ coating, the $\mathrm{TiC}$ in the coating mainly presents as undermelted, fine particles, and dendritic morphology. From the bottom of this coating to the surface, the particle size of the undermelted $\mathrm{TiC}$ shows a clear gradient change. Finally, the $30 \% \mathrm{TiC}+\mathrm{Co} 50$ coating does not have in situ $\mathrm{TiC}$, and there is no obvious gradient change in the particle size of undermelted TiC. After coating by the LD method, the surface hardness is strongly enhanced. The average hardness of Co50 alloy, Co+10\% TiC, and Co+20\% TiC composite coatings is $499 \mathrm{HV}_{0.2}, 552$ $\mathrm{HV}_{0.2}, 590 \mathrm{HV}_{0.2}$, and $824 \mathrm{HV}_{0.2}$, respectively. These values are 2.4-4.0 times harder than that of the H13 substrate. The wear resistance of $\mathrm{Co} 50$ alloy, $\mathrm{Co}+10 \% \mathrm{TiC}$, and $\mathrm{Co}+20 \% \mathrm{TiC}$ composite coatings is greatly higher than that of $\mathrm{H} 13$ steel, showing excellent wear characteristics. The friction coefficient of the coatings which have TiC is very stable. Therefore, the coatings can satisfy the requirement of tool steels applications. Additionally, the wear mechanism of the coating at room temperature is mainly brittle spalling, adhesive, and ploughing. At $700^{\circ} \mathrm{C}$, the wear mechanism is mainly oxidation and fatigue.
\end{abstract}

\section{Introduction}

The surface of alloy tool steels and hot-working steels require high-temperature resistance, high strength, and high toughness. Particularly, these kinds of steel need high ability of abrasive resistance and thermal fatigue at high temperatures. After some heat treatment processes such as quenching and tempering, the hardness and the strength of the steel are enhanced greatly. However, the critical working conditions at high temperate could cause damage, fatigue failure, and creep on the steel surface. Therefore, the working ability of the tools is reduced and the product quality also suffers a decrease $[1,2]$.
In recent years, laser cladding (LC) is one of the advance surface modification methods that could improve the surface quality of the materials by creating a functional coating on the substrate surface. This method is rapidly developed and applied to repairing and recovering tool steel surfaces, especially at large surface tools like pressing mold, drawing mold, and rolling axis [3-10]. In LC technology, ceramic particle-reinforced metal-based composite coatings have become a hotspot in recent years due to their excellent wear resistance, corrosion resistance, and high-temperature oxidation resistance [11-14]. Among some feeding materials for the LC technique, Co-based alloy coating material can strongly increase the antioxidation and abrasive abilities for 
the coated surface. But when suffering high friction force, the hardness and the abrasive characteristic of this type of coating still need further improvement. Therefore, various carbides, nitrides, and silicides particles are often used as composite reinforcement components.

Recent reports focus on adding some type of carbide particles such as $\mathrm{WC}, \mathrm{B}_{4} \mathrm{C}, \mathrm{SiC}$, and $\mathrm{Cr}_{2} \mathrm{C}_{3}$ to the Co-based alloy coating to increase the abrasive and mechanical properties at the high-temperature environment of the working surface [15-18]. Among these reinforcement phases, TiC with high hardness, high melting point, stability at the high-temperature environment, and easiness to disperse is an excellent wear-resistant ceramic strengthening phase. In the field of wear resistance and high-temperature resistance, it has received considerable attention from the material science community. However, when combined with Co-based alloy, thermal stress, voids, and microcracks can appear due to the relatively large thermal expansion coefficient difference between $\mathrm{TiC}$ and Co metal. The mechanical properties of ceramic reinforced composites depend on the morphology, particle size, content, crystal integrity, and distribution of particles in the composite phases [19-21]. To achieve a perfect coating of Co-based alloy mixed with the TiC particle, the size of the particle is one of the most important factors. The smaller the particle size, the fewer the defects, while the smaller the average free path of the bonding phase, the higher the bending strength and hardness can be maintained. Moreover, the clearer its strengthening effect, the less unfavourable the toughness and plasticity. The larger the particle size, the worse the strengthening effect, therefore, this effect can disappear, the greater the degree of disadvantage to toughness and plasticity [22-24].

However, there are few reports on the formation mechanism under the conditions of overequilibrium rapid solidification [25-27]. For that reason, it is particularly important to study the morphology of $\mathrm{TiC}$ in coatings. This paper used Co50 alloy and $\mathrm{TiC}$ mixed powder as raw materials and applied LC technology. By rationally adjusting the ratio of the two powders in the cladding layer and optimizing the cladding process parameters, a $\mathrm{TiC}$ reinforced Co-based composite coating is prepared on the surface of the $\mathrm{H} 13$ steel layer. The morphological characteristics and growth mechanism of TiC in the coating are analysed. The paper provides a theoretical and technological basis for the promotion and application of laser cladding technology in strengthening wear-resistant surfaces. Friction abrasion is a complex process, influenced by many factors such as hardness, surface morphology, temperature, and pressure [28-33]. Recently, the friction and wear properties of cladding layers have been widely studied at room temperature. However, there are not many researches focusing on friction and wear properties and its microstructure at high temperatures. Particularly, the effect of adding $\mathrm{TiC}$ in laser cladding coating has not been reported yet. This paper considers the wear resistance and hardness of Co-based alloy coatings and TiC/Co-based composite coatings. Through analyzing the wear characteristics, the mechanisms of friction and wear resistance were indicated to provide useful knowledge for practical applications.

\section{Materials and Methods}

ASTM H13 hot-working steel is chosen to be the substrate; the sample size is $100 \mathrm{~mm}$ length $\times 30 \mathrm{~mm}$ width $\times 10 \mathrm{~mm}$ thickness. The chemical composition of H13 steel sample is presented in Table 1, indicating a high-quality steel. The steel samples are initially ground by sandpapers and then cleaned by alcohol and acetone, following a drying step by an oven. Self-melting Co50 powder with the particle size of about $53 \mu \mathrm{m}$ is prepared; its chemical composition is shown in Table 2. The particle size of $\mathrm{TiC}$ is about $10 \mu \mathrm{m}$; the purity of $\mathrm{TiC}$ is $99.5 \%$.

The mixtures of Co powder with $0 \%, 10 \%, 20 \%$, and $30 \%$ TiC are created and scattered along the substrate surface with $1 \mathrm{~mm}$ thickness, as shown in Figure 1. After that, these samples are dried in an oven for 8 hours. Finally, the dried samples are melted by using the LC method. The LC process is made by laser cladding machine GS-TFL $6000 \mathrm{CO}_{2}$ at Kunming University of Technology. Some basic technical parameters are laser beam power $3.3-3.6 \mathrm{~kW}$, scanning speed $350-500 \mathrm{~mm} / \mathrm{min}$, the distance of the laser head to the substrate surface $50 \mathrm{~mm}$, and inert gas argon flow rate $8 \mathrm{l} / \mathrm{h}$, as shown in Table 3.

The coated samples are cut by a laser-cutting machine in a direction that is perpendicular to the scanning direction. Then, the So sample is etched by aqua regia solution $\left(1 \mathrm{HCl}+3 \mathrm{HNO}_{3}\right)$ in 15 seconds, while $\mathrm{S} 1, \mathrm{~S} 2$, and S3 are etched by saturated $\mathrm{FeCl}_{3}$ in $\mathrm{HCl}$ solution for 2 minutes. After cleaning and drying, the etched samples are observed by a scanning electron microscope (SEM). The SEM type XL30ESEM-TMP (the Netherlands) has in situ accessories such as phoenix, OIM, and Energy Dispersive X-Ray Spectroscopy (EDS) for analyzing the microstructure and chemical composition of the coating. An X-ray diffraction (XRD) machine type D/MAX-3B (Japan) is used to study the crystal structure and phases of the samples. The microhardness testing is employed on the HMV-WIN machine, with the loading weight being $1.961 \mathrm{~N}\left(\mathrm{HV}_{0.2}\right)$, and the loading time is 15 seconds. The interface between the coating and the substrate is chosen to be the zero origin coordinate, in which the upper coating layer has a positive value, while the lower substrate layer has a negative value.

This research uses wear-by-friction testing machine at high-temperature type MMU-5G to study the wear resistance of coatings at room temperature and at $700^{\circ} \mathrm{C}$ with pinon-disc wear of friction pairs. Some main technical indicators are as follows: the working range of the axial test force is $10-5000 \mathrm{~N}$; the relative error of the test force indication value is $1 \%$; the maximum friction torque is $5 \mathrm{~N} \cdot \mathrm{m}$; the relative error of the friction torque indication is $\pm 2 \%$; singlestage transmission system $0.1-2000 \mathrm{r} \cdot \mathrm{min}^{-1}$; spindle speed error is $\pm 1 \%$; and the temperature of the cylindrical heating furnace is $1100^{\circ} \mathrm{C}$, using $2 \mathrm{~K}$-type thermocouples.

\section{Results and Discussion}

3.1. Analyzing the Coating Phases by XRD Spectrum. Figure 2 represents the XRD spectrum of S0, S1, S2, and S3 samples. The results show that S0 coating consists mainly of 
TABle 1: Chemical composition of H13 steel sample used in the experiment (weight).

\begin{tabular}{lccccccc}
\hline Element & $\mathrm{C}$ & $\mathrm{Si}$ & $\mathrm{Mn}$ & $\mathrm{Cr}$ & $\mathrm{Mo}$ & $\mathrm{V}$ & $\mathrm{Fe}$ \\
\hline$\%$ & 0.43 & 1.17 & 0.48 & 4.79 & 1.38 & 0.94 & Bal. \\
\hline
\end{tabular}

TABLe 2: Chemical composition of Co powder used in the experiment (weight).

\begin{tabular}{lccccccccc}
\hline Element & $\mathrm{C}$ & $\mathrm{W}$ & $\mathrm{Si}$ & $\mathrm{B}$ & $\mathrm{Cr}$ & $\mathrm{Mo}$ & $\mathrm{Fe}$ & $\mathrm{Co}$ & $\mathrm{Ni}$ \\
\hline$\%$ & 0.6 & 3.0 & 3.5 & 2.25 & 20.0 & 5.1 & 5.0 & Bal. & 14.0 \\
\hline
\end{tabular}

the $\gamma$-Co phase, which has the highest peak, and $\mathrm{Cr}_{1 \cdot 12} \mathrm{Ni}_{2} .88$ phase. The lattice structure of $\gamma$-Co is face center cubic (FCC). Normally, at a temperature higher than $417^{\circ} \mathrm{C}$, pure Co has an FCC structure; however, at a lower temperature, Co lattice transforms into hexagonal close-packed (HCP) $\mathcal{E}$-Co style. Otherwise, the XRD diagram illustrates an FCC structure of $\gamma$-Co rather than an HCP structure of $\varepsilon$-Co as the existence of the $\mathrm{Ni}, \mathrm{W}$, and Fe elements on the Co50 powder. These elements tend to stabilize the FCC structure. Besides, the LC method generates a superrapid cooling rate of the molten powder when creating a coating; thereby, the $\gamma$-Co structure does not have time to transfer into $\varepsilon$-Co. These are the reasons why the coating structure consists mainly of $\gamma$-Co. Besides Co element, the solid solution of $\gamma$-Co dissolves some other elements $[1,20] . \mathrm{Cr}_{1.12} \mathrm{Ni}_{2.88}$ phase is generated by the crystallization rate and cooling rate that are extremely fast in the LC method. This phase can also dissolve a small amount of other elements.

Figure 2 also indicates that the coating of $\mathrm{S} 1$ sample is formed of $\mathrm{TiC}, \mathrm{TiCo}_{3}, \mathrm{Cr}_{2} \mathrm{Ni}_{3}$, and $\mathrm{Cr}-\mathrm{Ni}-\mathrm{Fe}-\mathrm{C}$ phases. $\mathrm{TiCo}_{3}$ phase is created by a reaction between Co elements in Co powder and Ti elements split up from TiC by LC heat, while $\mathrm{Cr}_{2} \mathrm{Ni}_{3}$ phase is formed by a reaction between $\mathrm{Cr}$ and $\mathrm{Ni}$ under the high power of a laser beam. On the other hand, $\mathrm{Cr}$ $\mathrm{Ni}-\mathrm{Fe}-\mathrm{C}$ phase in $\mathrm{S} 1$ sample is generated by the elements in Co50 powder, Ti elements split up from $\mathrm{TiC}$, and some elements diffused from the steel substrate. The coating of S2 sample is made of $\mathrm{TiC}, \mathrm{Cr}_{2} \mathrm{Ni}_{3}$, and $\gamma$-Co, while $\mathrm{S} 3$ sample coating consists mainly of $\mathrm{TiC}$ and $\gamma$-Co.

In summary, the solid solution $\gamma$-Co exists in the coating of S0, S2, and S3 samples but does not exist in the coating of S1 sample. In the coatings of S1, S2, and S3 samples that are having $\mathrm{TiC}$ on the mixture powder, increasing the $\mathrm{TiC}$ percentage results in decreasing the percentage of $\mathrm{Cr}_{2} \mathrm{Ni}_{3}$. $\mathrm{Cr}_{2} \mathrm{Ni}_{3}$ phase exists in the coatings of $\mathrm{S} 1$ and $\mathrm{S} 2$ samples, but cannot be found on the S3 sample.

Figure 3 demonstrates the microstructure of S0, S1, S2, and $\mathrm{S} 3$ coatings. It can also be seen that from the top of S0, S1, and S2 samples, the microstructure includes bonding zone (BZ), cladding zone (CZ), heat-affected zone (HAZ), and steel substrate. The microstructure of the S0 sample has a good microdensity and a good metallurgical bond that is formed between the coating and the substrate, with the thickness of the coating being low. The microstructure of the S2 sample indicates a better structure, and the coating thickness is larger than that of the S1 sample. The coating thickness of the S3 sample is the largest, but the coating and substrate are not well combined. There are no bonding regions caused by the high $\mathrm{TiC}$ content in the coating, so the quality of this S3 coating is not good enough.

In the superrapid melting process, the energy intrusion amount of the laser beam into the steel substrate is dramatically small. That is the reason why the sensitivity HAZs are ultrathin, with $788 \mu \mathrm{m}$ for $\mathrm{S} 0,722 \mu \mathrm{m}$ for S1, and $590 \mu \mathrm{m}$ for S2. The thinner the HAZ, the better the quality of the sample. In addition, the martensite grain size of HAZ is bigger than the martensite grain in substrate. Because the substrate is affected by the huge heat energy of the laser beam, some grains grow larger as they merge with the neighbor grain. But in the LC process, this heat-affected zone happens in an extremely short time. The growing grain does not have enough time to grow too large; therefore, the mechanical properties of the HAZ remain in good condition. This is the impressive advantage of LC method. The LC technical parameters are important factors that strongly affect the quality of the coating. When the technical parameters are well controlled, the microstructure of the LC coatings can prevent heat stress, residual stress, and microcracks.

Figure 4 illustrates the microstructure of the cross section of S1, S2, and S3 coating samples. It can be seen from Figures $4(\mathrm{a})-4$ (c) that the coating and the substrate interface show a clear "white bright band," showing that the coating and the H13 steel substrate can achieve a good metallurgical bond. In laser cladding, the "white bright band" is extremely thin $(2 \sim 5 \mu \mathrm{m})$. The molten powder is cooled down at the highest rate at this interface, generating a fine grain structure with uniaxial orientation. These grains can quickly grow to form a dendritic crystal. The dendrite with the main branch grows parallel and in reverse direction to the heat flux (perpendicular to the substrate) at a high speed. Other dendrites with the main branch which are not perpendicular to the substrate cannot grow because they are surrounded by other crystals. Consequently, the crystal with the highest growing speed will form the morphology of the solid-liquid interface and leads to the formation of the columnar grains. Their columnar grains have a flat boundary and grow in the reverse direction to the heat flux. They are the white bonding lines. It means that $\mathrm{S} 1$ and $\mathrm{S} 2$ coatings construct a strong bonding with the H13 steel substrate. Above these white lines, the TiC particles with black color appear. The density and size of the black TiC particles increase as the increase in the ratio of the $\mathrm{TiC}$ in the mixture powder. In S3 coating, there are too many $\mathrm{TiC}$ particles that result in a limitation in a good bonding zone.

In S0 coating, the "bright band" is a quite flat-growth tissue. Because the laser energy is transmitted downward from the top of the cladding layer, and the tissue solidifies from bottom to top, the heat action time at the bottom of the cladding layer is short, and the tissue growth rate is slow. Therefore, flat interface grows. This "bright band" is substantially perpendicular to the plane and cell crystals growing at the interface. To the middle of the molten pool, multidirectionally grown dendrites and dendrites are transformed. The near-surface is a fine dendrite region 


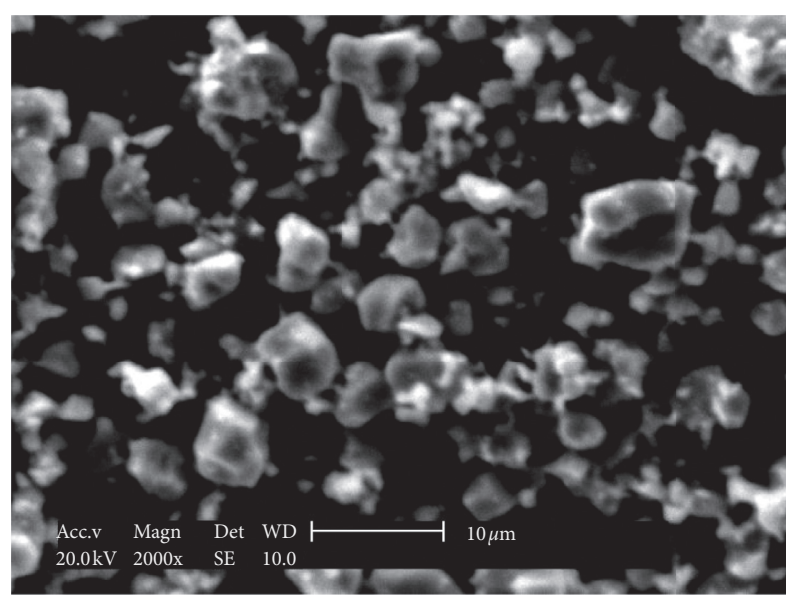

(a)

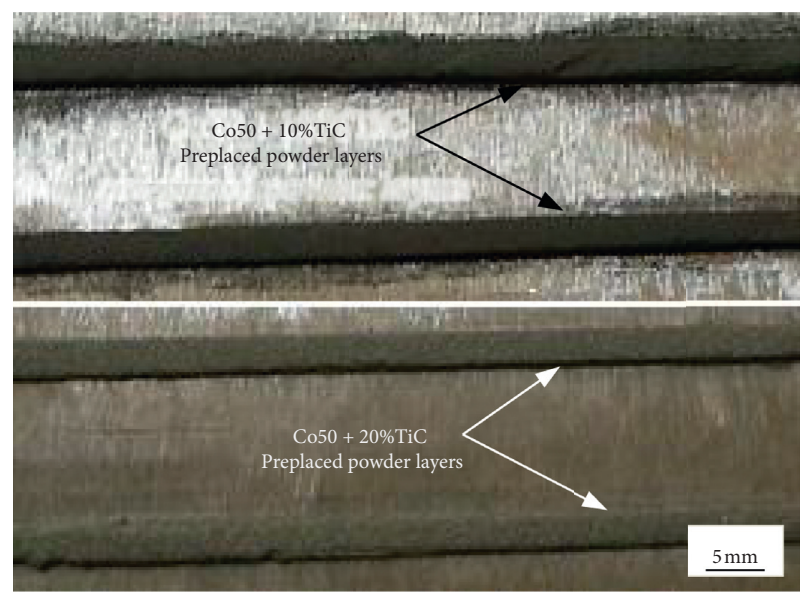

(b)

Figure 1: TiC powder used for laser cladding. (a) Topography of TiC. (b) TiC/Co-based preplaced powder layers.

TABLE 3: Technical parameters and sample surfaces of LD method applied in the experiment.

\begin{tabular}{lcc}
\hline Sample & Co50 (\% wt.) & TiC (\% wt.) \\
\hline S0 & 100 & 0 \\
S1 & 90 & 10 \\
S2 & 80 & 20 \\
S3 & 70 & 30 \\
\hline
\end{tabular}

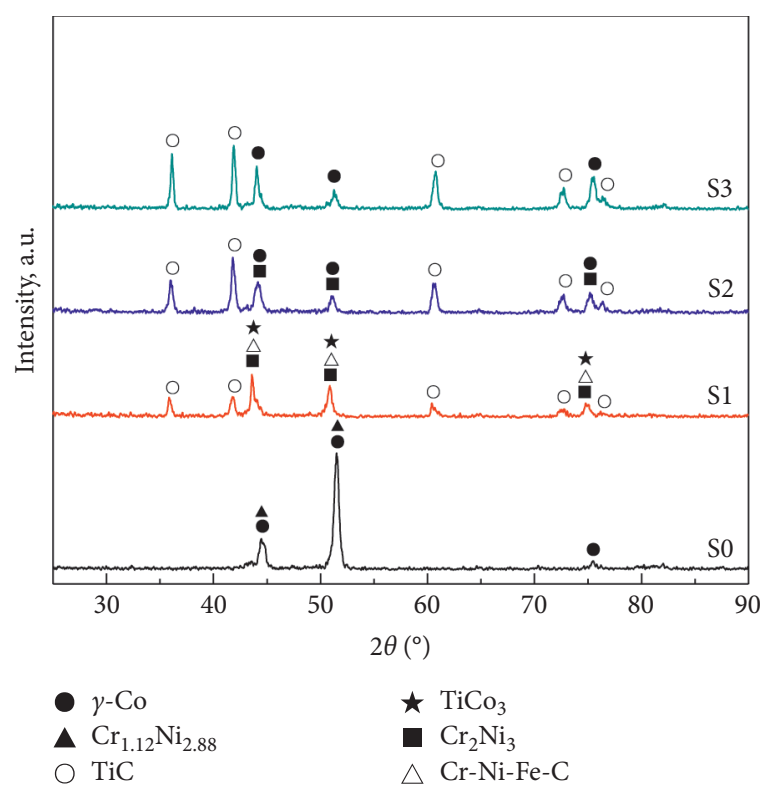

Figure 2: XRD spectrum of S0, S1, S2, and S3 coatings.

that grows parallel to the direction of the laser scanning speed. This is because the temperature of the substrate is low and heat is dissipated fastest in a direction perpendicular to the cladding layer. In addition, the dendrite structure of the coating gradually disappeared from the bottom to the surface, and it turned into a large number of dense fine structures near the coating surface. The edge of the bonding zone of the S0 coating has obvious growth characteristics of columnar dendrites and equiaxed crystals and solidifies and develops towards the coating surface perpendicular to the bonding zone. Zhang's research shows that there is an equiaxed crystal chill layer near the base in the cladding layer of Co-based alloy, therefore producing a large degree of subcooling [14]. Compared with the S0 coating, a "white bright band" of the S1 and S2 coatings is wider, which will help increase the bonding strength between the coating and the substrate. It can be seen that the structure of the $S 1$ coating is composed of bright white dendrites, eutectics between the dendrites, and black $\mathrm{TiC}$ particles, and the $\mathrm{TiC}$ particles are diffusely distributed, which can play a good hardening role. The morphology of $\mathrm{TiC}$ in the $\mathrm{S} 1$ coating structure is different due to its different parts in the molten pool; its composition, temperature distribution, and cooling rate are different. $\mathrm{TiC}$ in the middle and the surface of the coating is a large block structure, while the bottom of the coating has a low temperature and insufficient melting, and the more rapid the heat transfer effect of the cold matrix, the larger the cooling rate, and the $\mathrm{TiC}$ grains are too late to grow. It has stopped growing when it is large, so a fine granular structure is formed. In addition, compared with the microstructure of the S0 coating, the structure of the $\mathrm{S} 1$ coating is no longer composed of neat columnar dendrites, and there is no obvious direction of dendrite growth. Many interdendritic eutectic structures exist.

In S2 coating with $20 \% \mathrm{TiC}$, the "white bright band" contains a large amount of black TiC particles. With the increase of the amount of $\mathrm{TiC}$ in the preset layer, the content of the $\mathrm{TiC}$ reinforcing phase and the phase structure of the coating evolve accordingly, while the size of the $\mathrm{TiC}$ particles in the structure increases and the number decreases slightly. The resulting $\mathrm{TiC}$ is evenly distributed in the coating. It can also be seen from the figure that the structure of the coating is composed of bright white dendrites, eutectics between the dendrites, and black $\mathrm{TiC}$ particles, and the $\mathrm{TiC}$ particles are dispersedly distributed, which can play a greatly hardening role. 


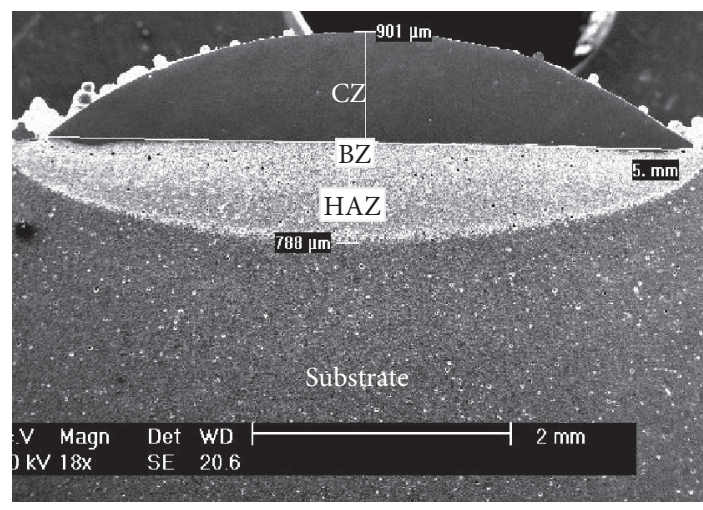

(a)

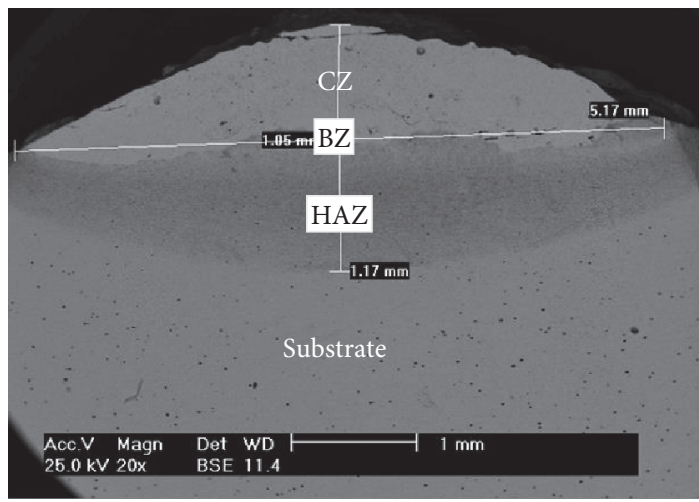

(c)

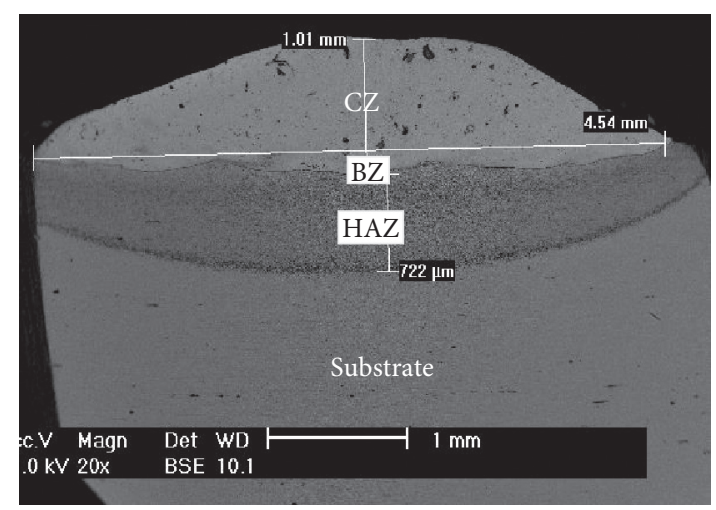

(b)

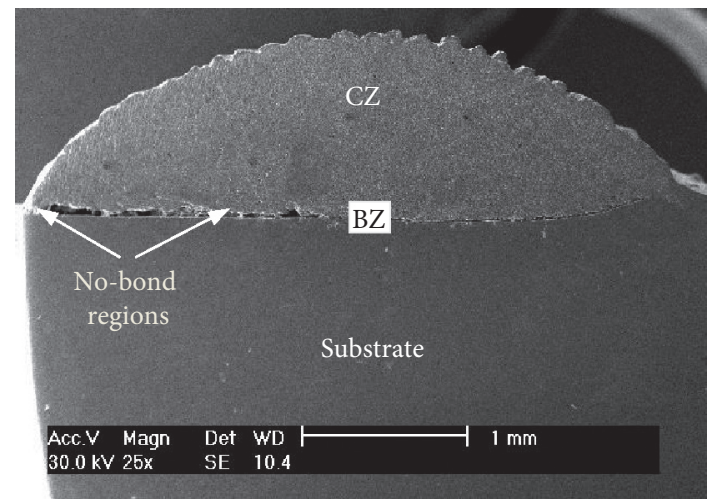

(d)

FIgURE 3: Microstructure of coatings. (a) S0 coating. (b) S1 coating. (c) S2 coating. (d) S3 coating (BZ: bonding zone; CZ: cladding zone; and HAZ: heat affected zone).

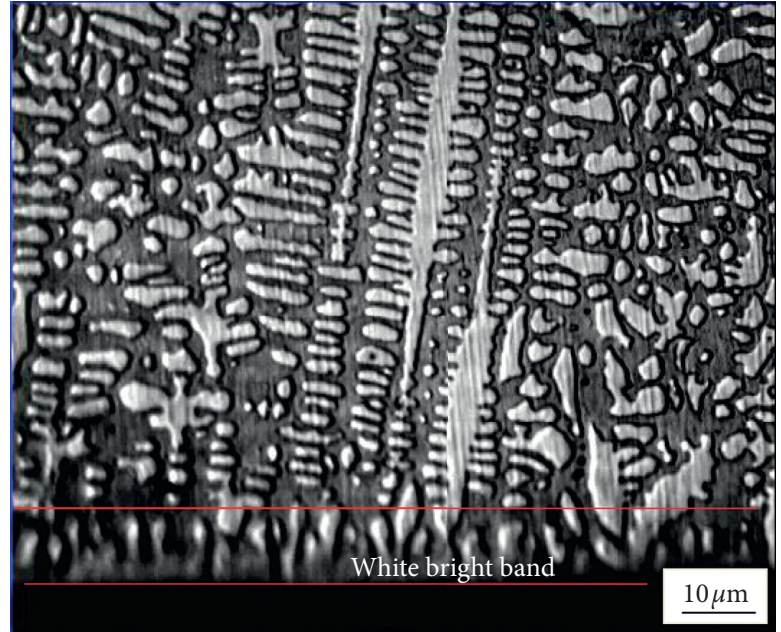

(a)

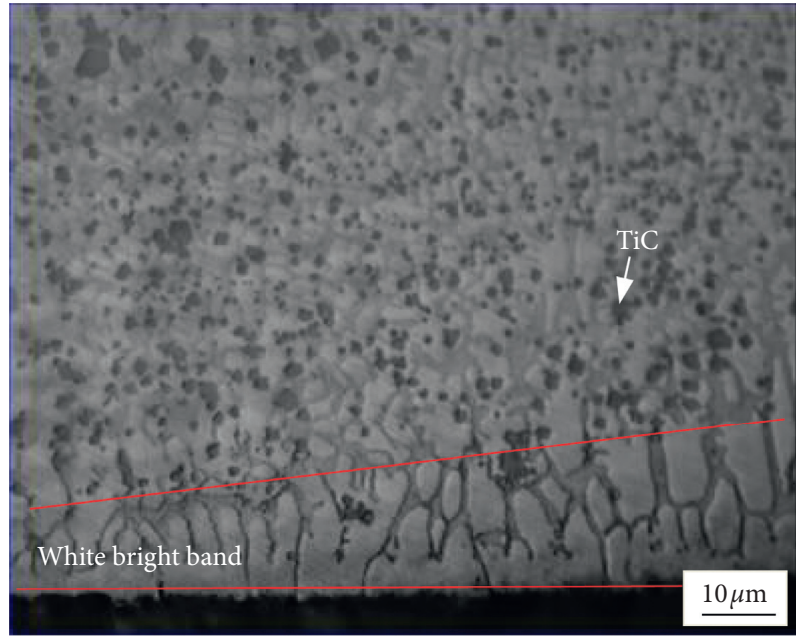

(b)

Figure 4: Continued. 


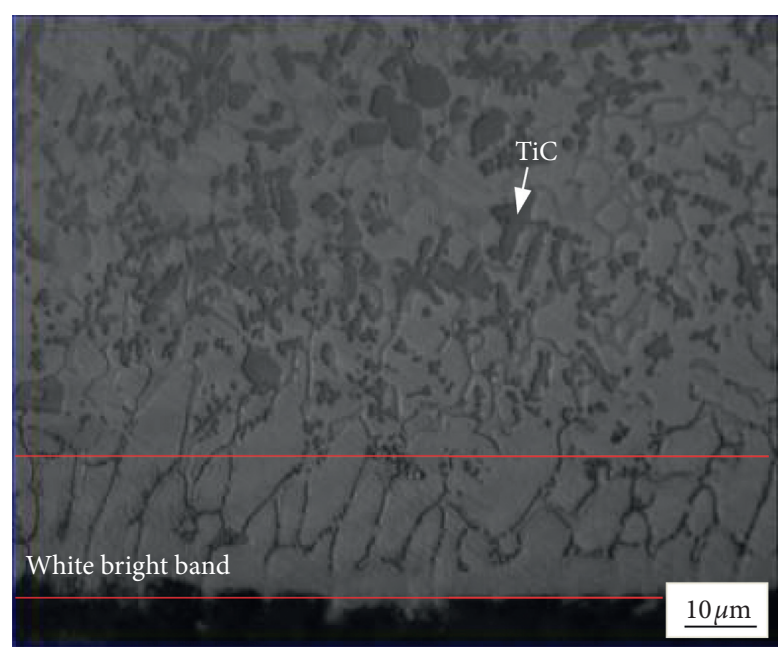

(c)

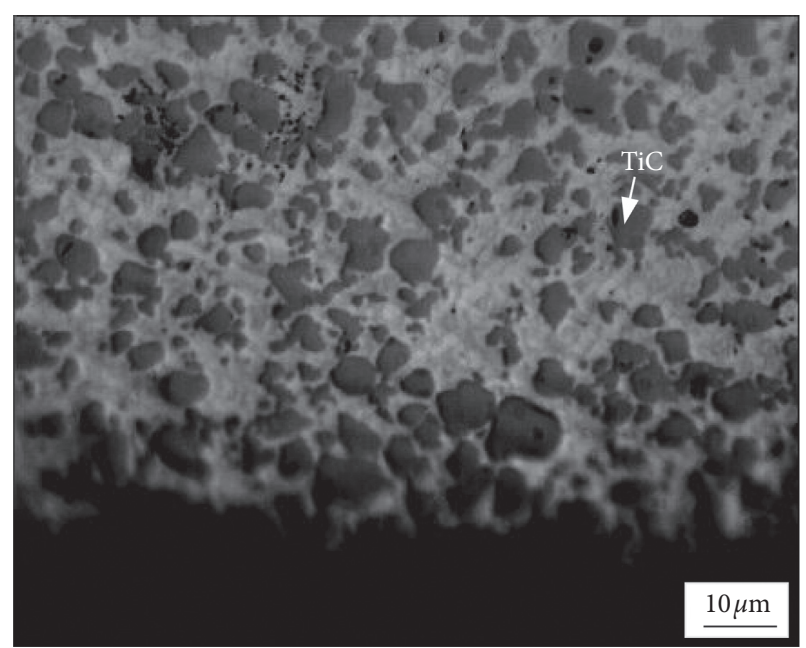

(d)

FIgUre 4: Microstructure of cross section of the coatings after LC process. (a) S0 coating. (b) S1 coating. (c) S2 coating. (d) S3 coating.

When the TiC content in the preset layer was increased to $30 \%$, the $\mathrm{S} 3$ coating did not achieve a good combination with the substrate, as shown in Figures 3(d) and 4(d). The reason is that the thermal expansion coefficients of $\mathrm{TiC}$ powders and Co-based alloy powders are quite dissimilar. Consequently, when the temperature gradient increases, the thermal stress and the formation of cracks generated by expansion increase. In addition, the required laser power density is related to the melting point; when the absorption rate is high, the required laser power density is greater. Studies by Si et al. $[17,18]$ found that if the content of added carbide reinforcing phase is too high, the brittleness of the coating will experience a significant increase. This is because the formation of a large amount of carbides, leading to the coating being prone to cracks and spalling during working operation.

Figure 5 shows the microstructure with different types of shapes of TiC on S1 coating. It can be seen that the coating structure is mainly composed of dendrites, eutectic structures between dendrites, and $\mathrm{TiC}$ particles. Besides the original $\mathrm{TiC}$ particles (black) that are not fully melted, there are also primary $\mathrm{TiC}$ particles (white) that are precipitated in situ from the liquid phase during solidification. Observing the morphology of $\mathrm{TiC}$, it can be found that from the bottom to the surface layer, the morphology of incompletely melted $\mathrm{TiC}$ is mainly spherical, while $\mathrm{TiC}$ precipitated in situ exists in different forms.

Figure 5(a) demonstrates that in the bonding zone, TiC particles have a white color with extremely fine size. Prior reports indicated that these fine $\mathrm{TiC}$ particles have a hexagonal shape and only appear near the white bonding lines, while most of the dense $\mathrm{TiC}$ particles near the bonding interface are randomly distributed, and the small TiC particles only appear at the bottom of the coating; away from the bonding interface, a large amount of fine $\mathrm{TiC}$ precipitates $[2,3]$. The growing mechanism of these particles is independent growth as the nuclei of TiC formed by the "floating" principle. The floating principles are caused by concentration, structure, and energy. These principles are helpful for the microstructure arrangement; for instance, $\mathrm{TiC}$ in liquid phase existing on the atomic cluster will gradually pile up to grow bigger to become a super fine TiC. According to the analysis, the reason that $\mathrm{TiC}$ is not fully melted is mainly due to the fact that when laser-cladding $\mathrm{TiC} / \mathrm{Co}$-based composite coatings, the composite material melts by absorbing the energy of the laser beam. The absorptivity of a material to a laser depends on the resistivity of the material, the scanning speed, and the wavelength of the laser [12].

Figures 5(b) and 5(c) show that a large amount of TiC particles gather together to form a blocky rosette, with two or three particles in a rosette [4]. From the bottom to the top of the coating, the number of $\mathrm{TiC}$ petals increases, and the particle size becomes larger. The orientation of different $\mathrm{TiC}$ particles in the petal-like morphology is disordered, showing random bonding and no obvious orientation characteristics. The different morphologies of $\mathrm{TiC}$ in different regions are caused by different cooling rates. On the other hand, the growth morphology of $\mathrm{TiC}$ is related to the solidification speed of the coating and the carbon concentration in the laser molten pool. The nucleus of these TiC particles are constructed by the incomplete molten $\mathrm{TiC}$ particle in the powder. It can be seen that TiC's growth mechanism in the middle zone of the coating is mainly in the form of a "bridge" [2]. Some $\mathrm{TiC}$ particles that are close to each other play roles as the central particles, and then they support each other and develop. On the top of the coating, $\mathrm{TiC}$ particles gather together to form clusters. In general, the number and the size of $\mathrm{TiC}$ clusters increase as they increase the distance from the bonding zone to the upper surface. This effect shows that, before the "capturing" phenomenon, the TiC clusters in the molten area were always moving. After that, they link together to generate bigger $\mathrm{TiC}$ clusters [3]. It can be explained that in the melting zone, parts of $\mathrm{TiC}$ particles resolve, assemble, and link with each other; each petal represents a TiC. Figure 5(a) 


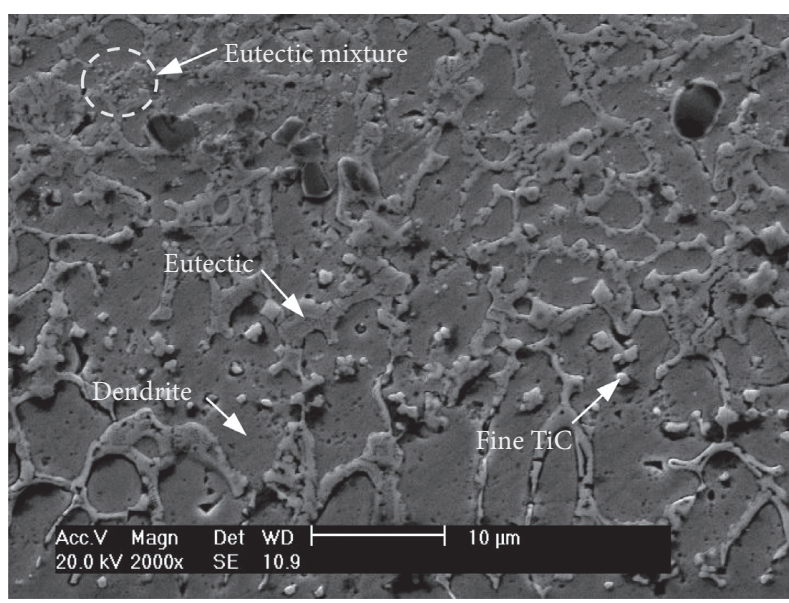

(a)

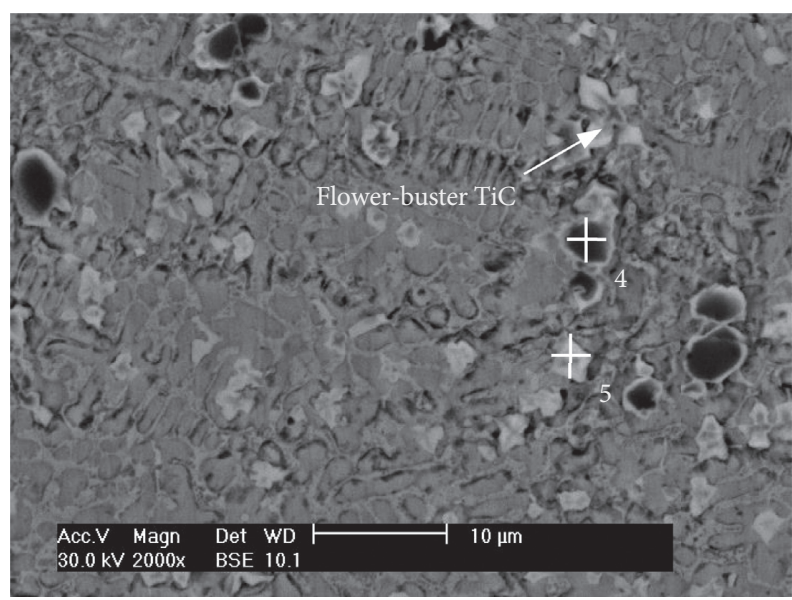

(c)

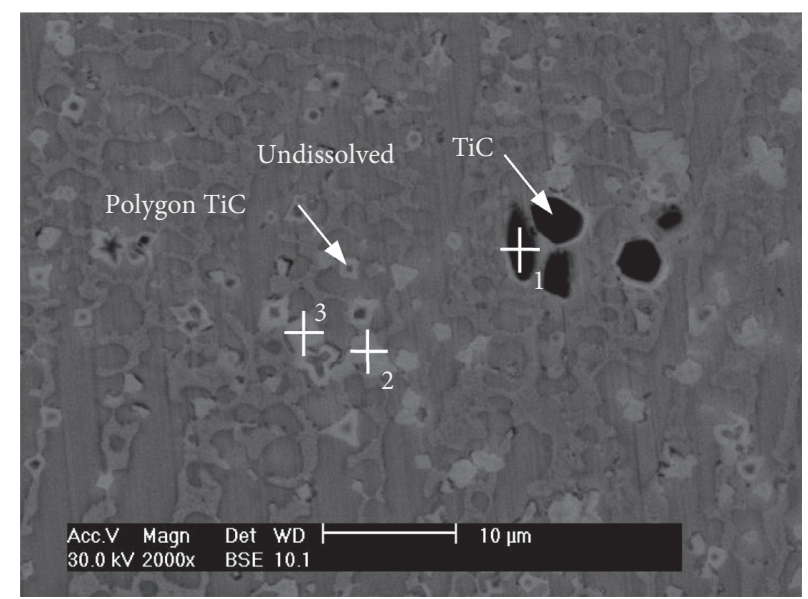

(b)

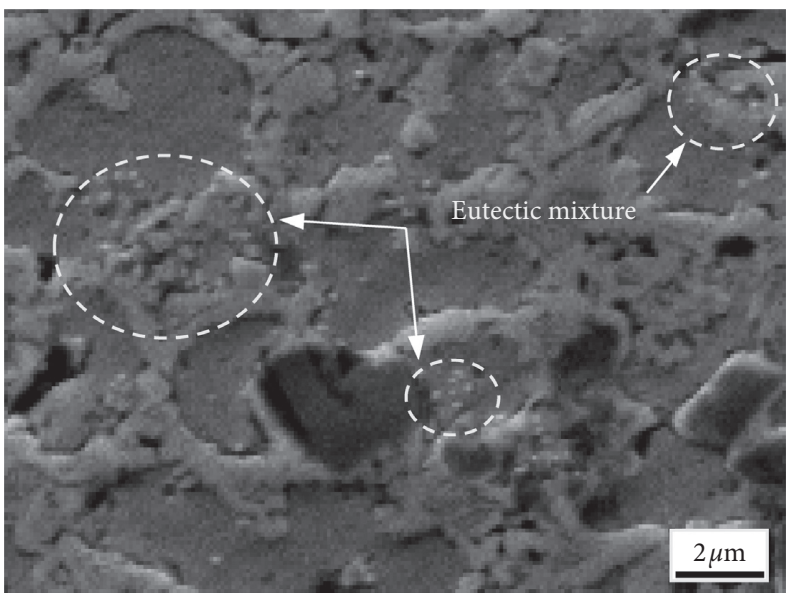

(d)

Figure 5: TiC morphologies in different regions of S1 coating. (a) Bottom part. (b) BSE micrograph of middle-part microstructure. (c) BSE micrograph of upper-part microstructure. (d) TiC eutectic mixture (primary TiC: small globe TiC; eutectic mixture TiC; and blocky rosette $\mathrm{TiC})$.

also indicates that a section of $\mathrm{TiC}$ can be observed as needleshaped, a similar result as Pei's report [5]. This is because when the temperature decreases, $\mathrm{Ti}$ and $\mathrm{C}$ atoms in the saturated $\gamma$-Co phase will separate and accumulate. The accumulation will form extremely fine $\mathrm{TiC}$ particles, and this phenomenon is called phase segregation. The phase segregation happens as a result of defects on $\gamma$-Co, therefore, forming vacancies. Karantzalis et al. [7] proved that the segregated $\mathrm{TiC}$ particles appear in many shapes: Chinese script shape, elongated precipitates shape, and fine-sized cuboid precipitates shape. Meanwhile, Pei [6] shows that the scanning speed of the laser beam seriously affects the shape of segregated $\mathrm{TiC}$ particles. The segregated $\mathrm{TiC}$ particles and recombinant $\mathrm{TiC}$ particles appear almost throughout the coating. The recombinant $\mathrm{TiC}$ particles grow in the direction that is parallel to the laser beam or they stack together. In summary, the diversity of the $\mathrm{TiC}$ particle shapes is caused by the effect of the close relationships between the $\mathrm{TiC}$ shape, the cooling rate, and the concentration of $\mathrm{C}$ in the melting region.

Because $\mathrm{TiC}$ powder absorbs laser energy much more than Co50 alloy, the resistivity of $\mathrm{TiC}$ is significantly higher than that of Co50 alloy. Hence, during the laser irradiation process, $\mathrm{TiC}$ preferentially absorbs heat and is rapidly heated to a very high temperature and then conducts heat to surrounding materials (heating matrix Co50 alloy). This heating mechanism makes the temperature of $\mathrm{TiC}$ and its nearby matrix Co much higher than the average temperature of the molten pool, which easily causes interfacial reactions. This indicates that the TiC particles were not completely melted during the laser cladding process, but mainly the surface melt-solidification process (black $\mathrm{TiC}$ particles that were not fully melted). It means that the nucleation of $\mathrm{TiC}$ mainly uses a large number of incompletely dissolved original TiC particles in the molten pool as the crystalline core, or it can grow independently. The existence of undermelted $\mathrm{TiC}$ and the precipitation of a large number of primary carbides make the structure of the cladding coating very fine.

The reason for $\mathrm{TiC}$ in situ precipitation is mainly because of the partial dissolution of TiC powder under the action of the laser. During laser irradiation operation, particles with residual deformation and distortion defects or $\mathrm{TiC}$ at the 
coating surface with higher cladding temperature may be completely dissolved, and large $\mathrm{TiC}$ particles also partially dissolve at their edges or raised parts [5]. At the same time, the melting point of the Co50 alloy is much lower than that of $\mathrm{TiC}$, so during the heat transfer process, Co50 in the mixed powder dissolves first, and $\mathrm{TiC}$ subsequently dissolves, causing the Co50 alloy melt to contain a large amount of supersaturated $\mathrm{Ti}$ and $\mathrm{C}$ atoms, forming a $\mathrm{C}$-rich region around it. The solid $\mathrm{C}$ particles quickly diffuse into the laser melt pool and are surrounded by Ti liquid. As the laser beam moves, the temperature of the molten pool drops rapidly, and these supersaturated $\mathrm{Ti}$ and $\mathrm{C}$ will reprecipitate from the melt. Because Ti atoms have a good affinity for $\mathrm{C}$ atoms, they preferentially combine to form TiC.

Under the laser beam effect, some $\mathrm{TiC}$ particles are resolved into $\mathrm{Ti}$ and $\mathrm{C}$. Solid $\mathrm{C}$ particles rapidly diffuse into the melting region and surrounded by liquid $\mathrm{Ti}$. The process of forming $\mathrm{TiC}$ consists of three stages. First, the contact surface between the liquid-solid phase of Ti and $\mathrm{C}$ directly reacts to form $\mathrm{TiC}_{\mathrm{x}}[2,5,8]$. Second, the liquid $\mathrm{Ti}$ continues to diffuse through $\mathrm{TiC}_{\mathrm{x}}$ layer to react with the remaining $\mathrm{C}$ in the core. The diffusion will continue until reaching the corresponding $\mathrm{TiC}$ concentration, forming molten $\mathrm{TiC}$ in the liquid phase. The solidification process happens at an extremely rapid rate, and the $\mathrm{TiC}$ separated from the liquid will segregate and grow. In addition, under the tremendously fast heating rate of the LC method, the separation rate in the melting zone of $\mathrm{TiC}$ is greater than Co due to a higher energy absorption of the TiC. A small number of $\mathrm{TiC}$ particles have high internal energy due to the appearance of residual stress or defects created in TiC powder making. For this reason, during the melting process, these particles are completely melted. The bigger TiC particles are also melted in the protruding part or at the edge. During the cooling process, some $\mathrm{Ti}$ and $\mathrm{C}$ atoms from the liquid phase recombine to form a new $\mathrm{TiC}$. At the end of the coating, besides the partly molten $\mathrm{TiC}$, the microstructure also consists of new forming $\mathrm{TiC}$ and $\mathrm{TiC}$ segregated from $\gamma$-Co.

According to the second law of thermodynamics, the reaction process always proceeds in the direction of the reduction of the free energy of the system. In other words, during the rapid solidification process, the synthesis of $\mathrm{TiC}$ is roughly divided into three stages. Initially, $\mathrm{Ti}$ and $\mathrm{C}$ at the solid-liquid bonding interface react directly to form $\mathrm{TiC}_{\mathrm{x}}$, as presented in Figure 6(b). Then, the liquid Ti diffuses and passes through the $\mathrm{TiC}_{\mathrm{x}}$ layer reacts with the remaining $\mathrm{C}$ until the concentration of $\mathrm{C}$ in $\mathrm{TiC}_{\mathrm{x}}$ reaches the concentration of $\mathrm{C}$ in $\mathrm{TiC}$, and the resulting $\mathrm{TiC}$ is dissolved in the liquid phase, as illustrated in Figure 6(c). Finally, TiC precipitates from the solution and grows $[9,10]$. This shows that $\mathrm{TiC}$ in situ can grow outside the original $\mathrm{TiC}$ particles along the edges or grow sideways with facet steps.

Comparing of in situ precipitation $\mathrm{TiC}$ and incompletely melted $\mathrm{TiC}$, incompletely melted $\mathrm{TiC}$ particles have some kind of defects such as burnout, interface pollution, and melting phase decomposition of enhanced phase during laser cladding, while $\mathrm{TiC}$ in situ precipitated particles are produced by in situ reaction. In this way, the thermal stability and interface problems of the enhanced phase are solved, and the coating performance is further improved. In addition, the incompletely melted $\mathrm{TiC}$ and $\mathrm{TiC}$ in situ properties are greatly different, while the incompletely melted $\mathrm{TiC}$ 's particle size and $\mathrm{TiC}$ in situ morphology have a great impact on the performance of $\mathrm{TiC} / \mathrm{Co}$-based coatings.

To provide more details about the composition of $\mathrm{TiC}$ particles, energy-dispersive X-ray spectroscopy (EDS) is used to analyze the particles in S1 sample, as shown in Figure 7. The results reveal that the black particles (point 1) and white particles (points 2 and 3 ) are composed mainly of $\mathrm{Ti}$ and $\mathrm{C}$. In point 1 , the atomic components of $\mathrm{Ti}$ and $\mathrm{C}$ are $36.32 \%$ and $49.39 \%$, respectively, and the atomic ratio Ti:C is 0.74 . In point 3 , the atomic components of $\mathrm{Ti}$ and $\mathrm{C}$ are $25.31 \%$ and $27.38 \%$, respectively, and the atomic ratio is 0.92 . From these numbers, it can be withdrawn that the atomic ratio between $\mathrm{Ti}$ and $\mathrm{C}$ is almost $1: 1$. This proves that the black and white particles in the microstructure of $\mathrm{S} 1$ are TiC. The black particles are nonmolten $\mathrm{TiC}$ or partially melting TiC, while the tiny white particles are the newly formed TiC. These new particles have a much smaller size compared to the black TiC particles. In point 2, the atomic percentages of $\mathrm{Ti}$ and $\mathrm{C}$ are $28.77 \%$ and $16.37 \%$, respectively, and the atomic ratio $\mathrm{Ti}: \mathrm{C}$ is 1.76 . At this point, the $\mathrm{TiC}_{\mathrm{x}}$ appears with a large amount of $\mathrm{C}$. The atomic percentage of point 4 is $35.15 \%$ and $39.06 \%$, and the atomic percentage of point 5 is $28.49 \%$ and $34.04 \%$, respectively. The atomic ratios of $\mathrm{Ti}$ and $\mathrm{C}$ in the particles are close to $1: 1$. Combined with the Ti-C phase diagram as demonstrated in Figure 7(f), it can be concluded that both black and white blocks are TiC. Among them, the black blocks are uncompleted melting $\mathrm{TiC}$, and the white blocks are in situ TiC. The size of the particles is much smaller than that of the undermelted TiC particles. Notably, the atomic percentages at point 2 are $28.77 \%$ and $16.37 \%$, respectively, and the $\mathrm{C} / \mathrm{Ti}$ atomic ratio is 1.76 , which indicates that $\mathrm{TiC}_{\mathrm{x}}$ still presents at point 2, and a large amount of $\mathrm{C}$ still remains.

The precipitation of $\mathrm{TiC}$ mostly uses the defects in the $\mathrm{Cr}-\mathrm{Ni}-\mathrm{Fe}-\mathrm{C}$ solid solution as a nucleation substrate. When the cooling process happens below the solidification temperature, the supersaturated $\mathrm{Ti}$ and $\mathrm{C}$ atoms in the $\mathrm{Cr}-\mathrm{Ni}-\mathrm{Fe}$ $\mathrm{C}$ solid solution precipitate. A fine-dispersed $\mathrm{TiC}$ precipitate is created and spread throughout the coating [13]. Pei's research [6] shows that the growth mechanism of tiny $\mathrm{TiC}$ particles is independent nucleation; that is, the independent nucleation of $\mathrm{TiC}$ in the liquid phase is based on the microlocation of favorable concentration fluctuations, structural fluctuations, and energy fluctuations, and then they stepwise stacking grow up and finally exist in the form of polyhedra in the form of close-packed atoms. TiC precipitates out because the supersaturated Ti in the $\gamma$-Co phase gradually precipitates when the solidification temperature continues to cool, forming small dispersed $\mathrm{TiC}$ particles. This precipitation mainly uses defects in the $\gamma$-Co solid solution as the nucleation site, and the dislocation lines firmly pin the precipitate. Zhang et al. [8] have confirmed that the $\mathrm{TiC}$ precipitates appear in the shape of Chinese characters, slender, and slender cubes. Pei et al. [5] also found that when the growth rate of the solid solution interface is greater than the critical speed of particle 


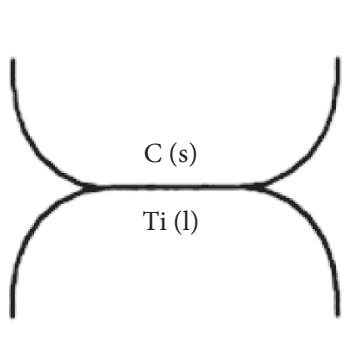

(a)
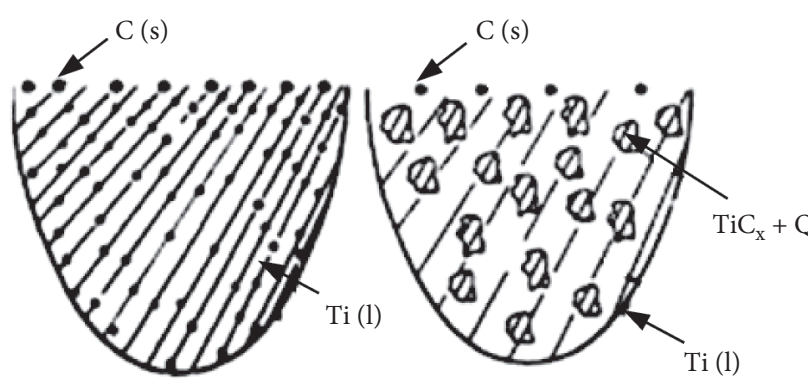

(b)

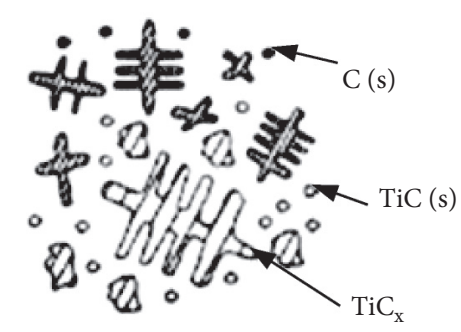

(c)

Figure 6: Model of TiC formation [5]. (a) Solid-liquid interface between Ti and C; (b) Ti and C directly reacted to form $\mathrm{TiC}_{\mathrm{x}}$; (c) the liquid $\mathrm{Ti}$ diffused through the $\mathrm{TiC}_{\mathrm{x}}$ layer, reacting with the remaining $\mathrm{C}$ and then $\mathrm{TiC}$ precipitated from the solution and grew up.

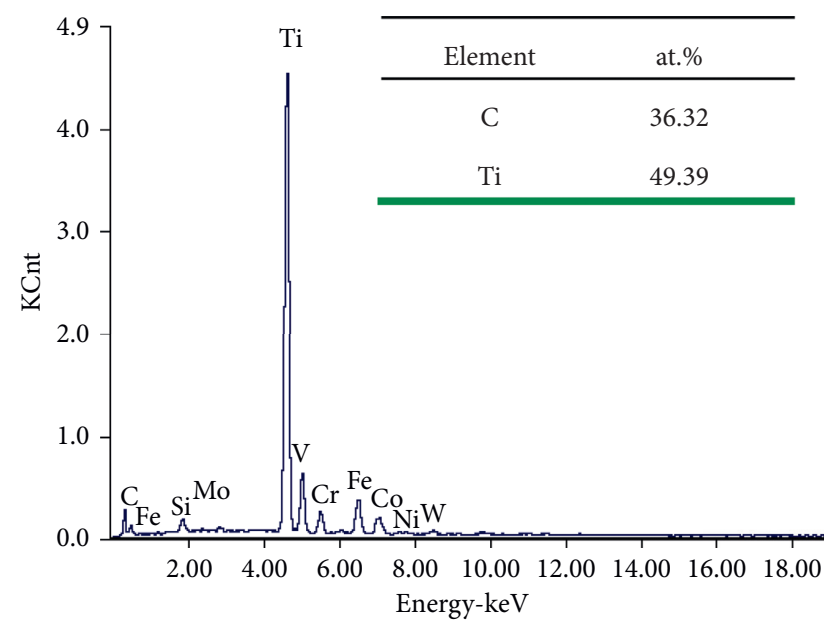

(a)

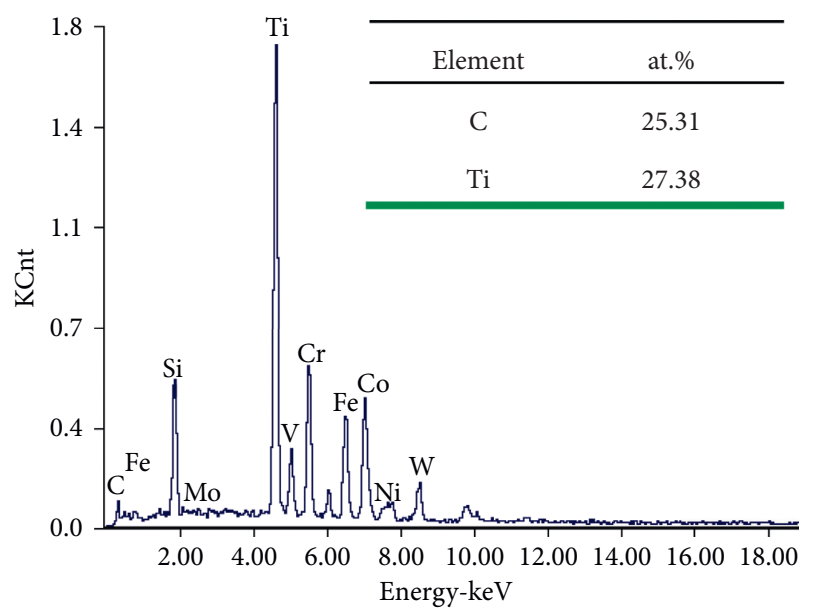

(c)

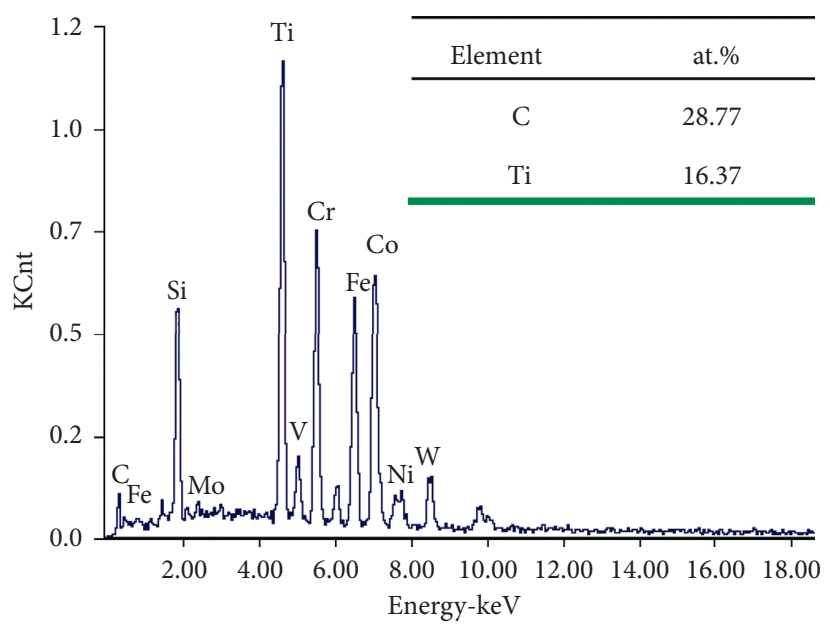

(b)

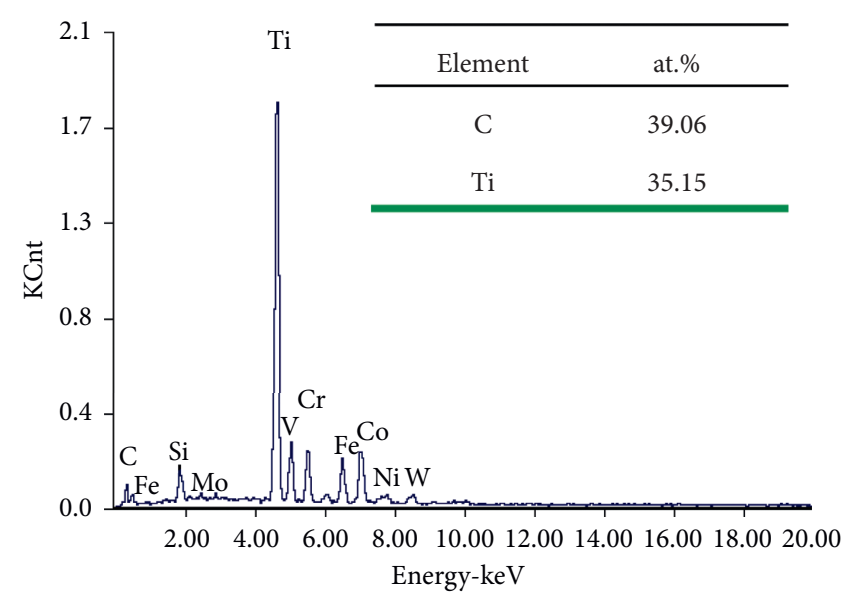

(d)

Figure 7: Continued. 


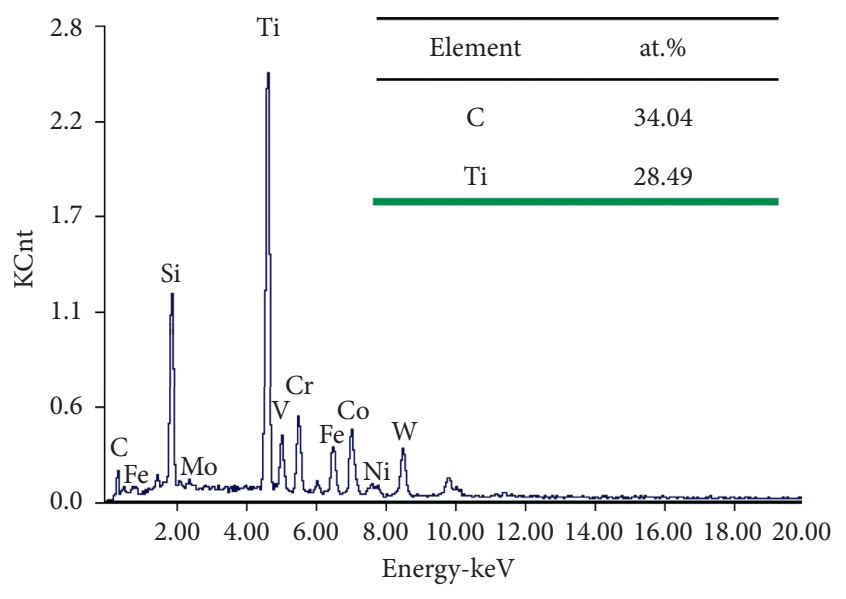

(e)

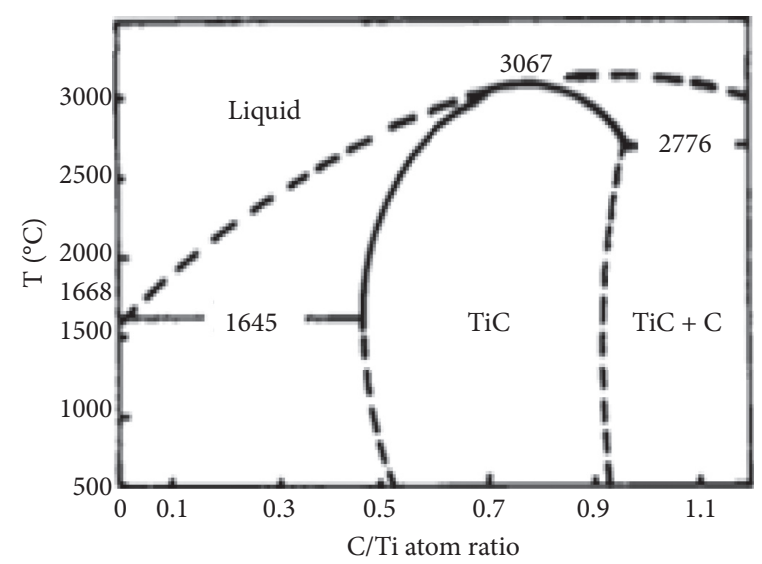

(f)

Figure 7: EDS spectrums of TiC from S1 coating. (a) Point 1. (b) Point 2. (c) Point 3. (d) Point 4 position. (e) Point 5 position. (f) Ti-C equilibrium phase diagram.

movement, $\mathrm{TiC}$ is captured by the interface and distributed in the solid solution crystals; otherwise, it is moved to the intercrystalline grains. The lotus petal-shaped nucleus mainly grows and connects with several incompletely melted original $\mathrm{TiC}$ particles close to each other as crystalline cores. Therefore, this morphological feature is a result of the in situ precipitation and aggregation of $\mathrm{TiC}$ particles, and each petal represents a TiC particle.

Figure 8 shows the microstructure with different types of shapes of TiC on S2 coating. From Figure 8(a), it can be seen that, like the $\mathrm{S} 1$ coating, small $\mathrm{TiC}$ particles precipitated in situ near the bonding interface of the S2 coating, and the small TiC particles only appear at the bottom of the coating. A magnified observation at $\times 16000$ showed that the surface of the small $\mathrm{TiC}$ particles was smooth, approximately spherical, and no obvious edges and corners. Figure 8(b) indicates a large amount of $\mathrm{TiC}$ in the form of cross petals [5] and twigs $[7,10]$. Around the bonding zone, the temperature is lower than the cladding zone, causing an incomplete melting. Moreover, the low temperature of the substrate leads to a rapid cooling rate. The growing time of the $\mathrm{TiC}$ is short, so it tends to keep the original shape or exist in any shape rather than growing bigger. Around the bonding zone, the shape petals are very symmetrical; this phenomenon is closely related to the crystal structure of $\mathrm{TiC}$. $\mathrm{TiC}$ lattice has an FCC structure, with both $\mathrm{Ti}$ and $\mathrm{C}$ atoms having symmetrical structural centers. Thereafter, when forming $\mathrm{TiC}$, the structure of $\mathrm{TiC}$ will tend to be symmetrical.

In Figures 8(c) and 8(d), TiC mostly exists in a spherical shape. In Figures $8(\mathrm{~b})-8(\mathrm{~d}), \mathrm{TiC}$ behaves in two ways in the alloy melt: one is that $\mathrm{TiC}$ has been completely dissolved and presents a large, densely distributed and developed dendritic morphology. Moreover, the developed dendrites are mostly cross-shaped and the orientation tends to be consistent; the second is that the TiC particles in the added powder are not completely dissolved and mainly exist as spherical structures, as displayed in Figures 8(c) and 8(d). Particularly, in the coatings, both dendrite and eutectic have a relatively uniform size, but the size of $\mathrm{TiC}$ varies greatly: from the bonding zone to the surface of the coating, the size of $\mathrm{TiC}$ gradually increases. This phenomenon is very clear and continuous. Chen and Wang [9] show that the shape of $\mathrm{TiC}$ is determined by the difference in position, composition, temperature distribution, and cooling rate in the coating.

The reason for the formation of the developed dendritic crystals of $\mathrm{TiC}$ is that part of the $\mathrm{TiC}$ in the coating is dissolved, and the $\mathrm{Ti}$ and $\mathrm{C}$ produced after the dissolution are solid-dissolved in the alloy melt. When cooling, a large number of polygonal lumps and primary $\mathrm{TiC}$ with other elements are solid-dissolved. A diffusion zone with high $\mathrm{Ti}$ and $\mathrm{C}$ content is formed around the unmelted TiC particles. During the solidification process, radial primary massive TiCs with unmelted $\mathrm{TiC}$ as the center appear, and then further cooling, so between the unmelted $\mathrm{TiC}$ and the primary $\mathrm{TiC}$, they are formed. The fine $\gamma$-Co dendrites and their eutectic structure were introduced. Due to the lower temperature and insufficient melting at the bottom of the coating, combining with the rapid heat transfer of the surrounding cold substrate, the cooling rate is extremely high, so the growth time of the precipitated $\mathrm{TiC}$ is dramatically shortened. It is too late to grow and maintain the initial state of the precipitation. During the nonequilibrium solidification process of laser cladding, primary $\mathrm{TiC}$ will appear when the $\mathrm{C}$ content in the liquid reaches a certain value. Since the space occupied by the ball is the smallest in the same volume, the primary $\mathrm{TiC}$ should exist in a spherical form, but it looks like the spherical $\mathrm{TiC}$ is actually a polyhedron, and the corners of the polyhedron have a small radius of curvature, a large concentration gradient of the solute, and a fast diffusion rate. Therefore, the crystals at the corners grow faster than the planes, making the polyhedron gradually grow into a dendritic shape [27].

Figure 9 shows the morphology of TiC in different areas of the $\mathrm{S} 3$ sample coating. The figure points out that $\mathrm{TiC}$ exists like a large number of diffusely distributed spherical structures. Unlike S2 coating, TiC particle size in S3 coating has no clear gradient change. This is because the TiC content is higher in the S3 coating, and the thermal expansion 


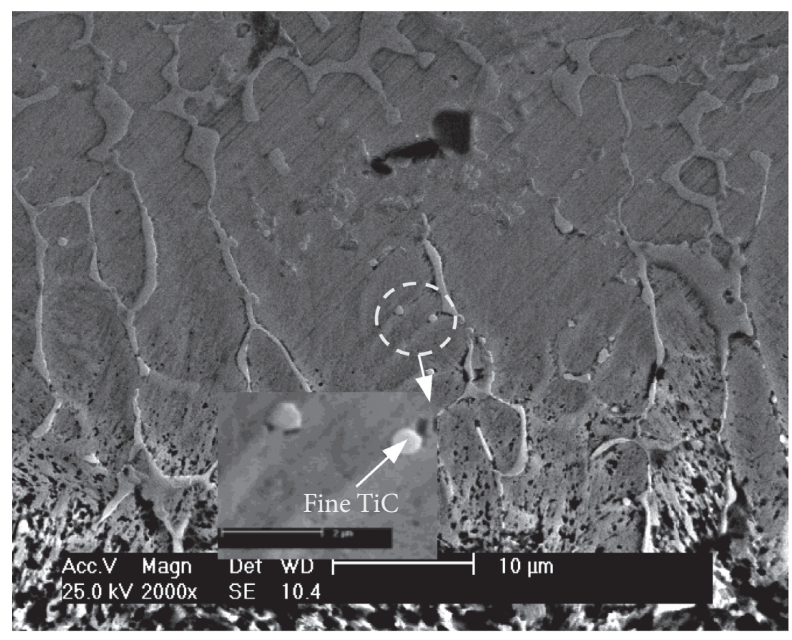

(a)

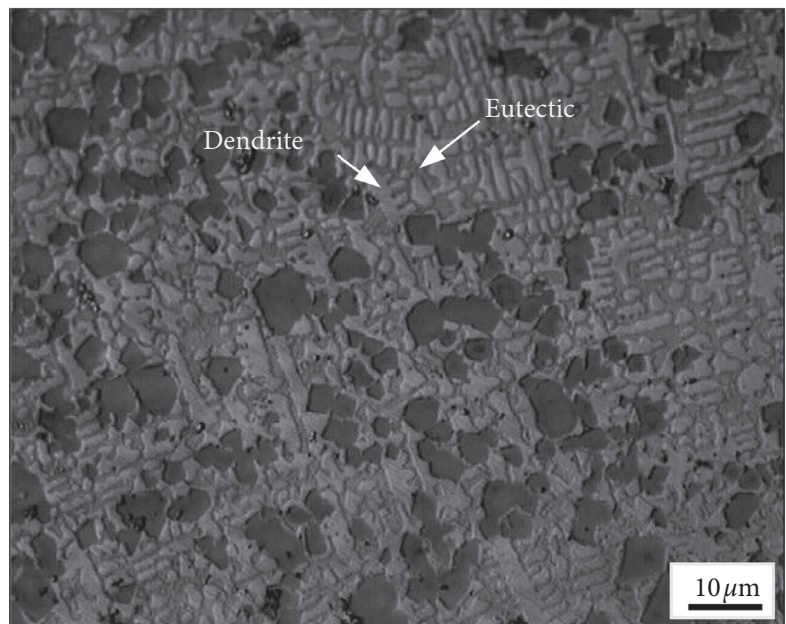

(c)

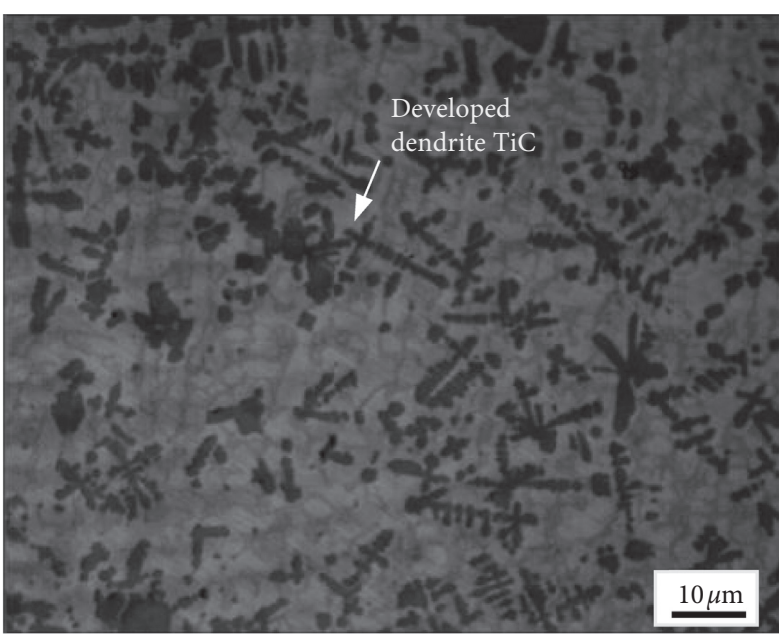

(b)

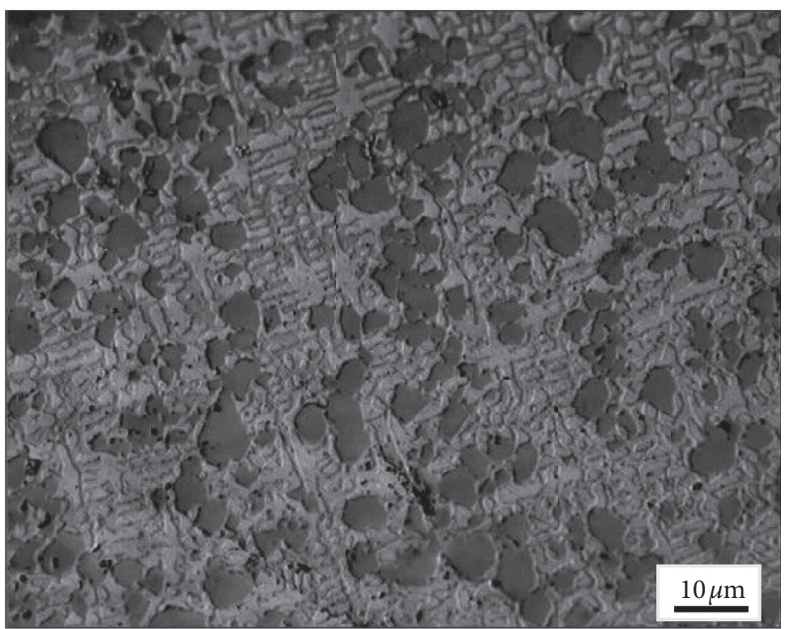

(d)

FIgURE 8: TiC morphologies in different regions of S2 coating: (a) bonding zone; (b) bottom part; (c) middle part; and (d) upper part.

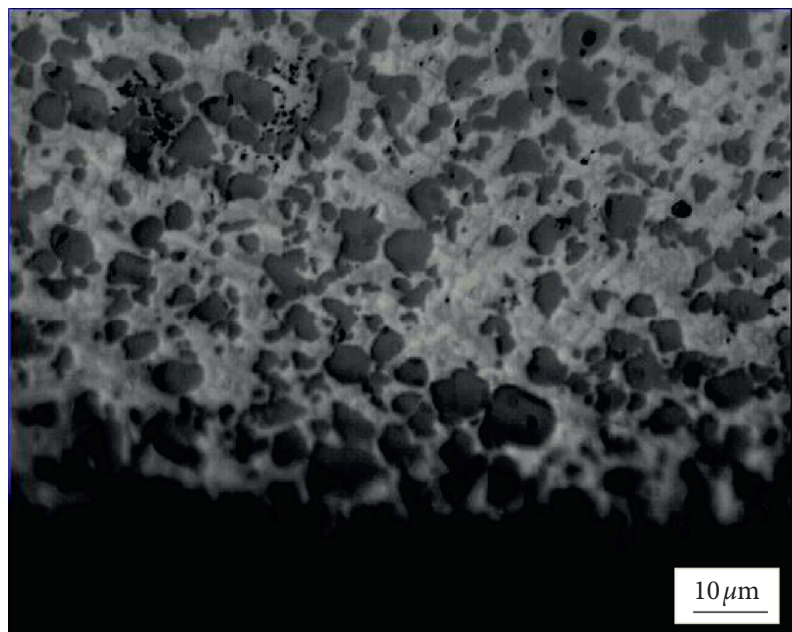

(a)

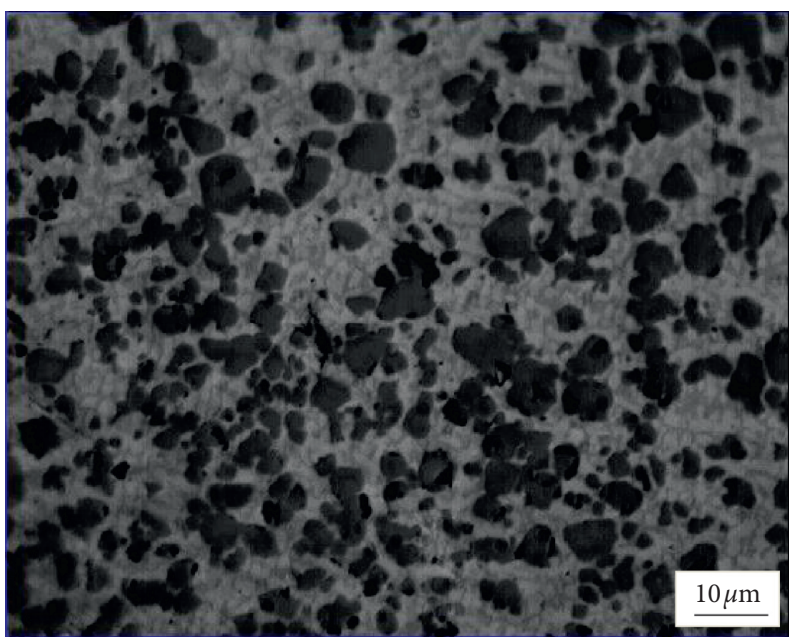

(b)

Figure 9: Continued. 


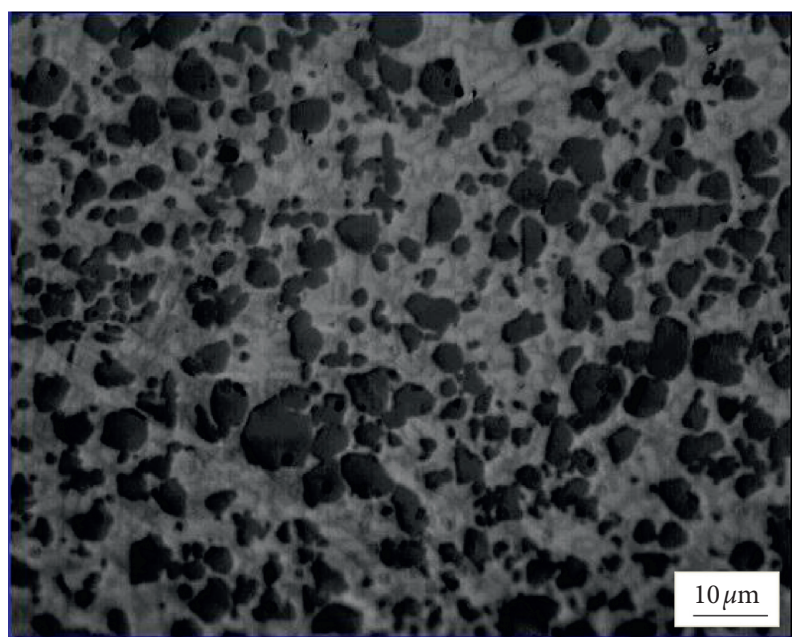

(c)

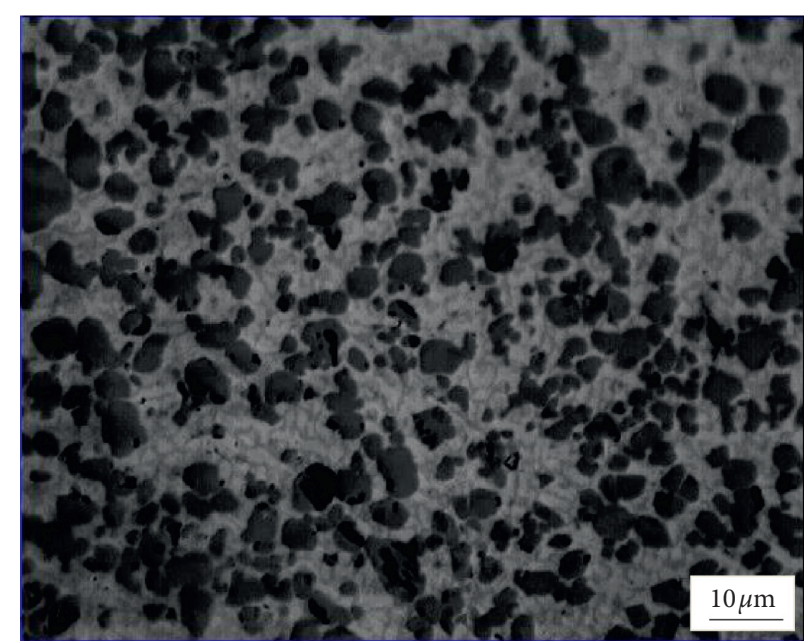

(d)

FIgURE 9: TiC morphologies of S3 coating: (a, b) bottom part; (c) middle part; and (d) upper part.

coefficients between $\mathrm{TiC}$ powder and Co-based alloy powder are very different. This will cause a large temperature gradient in the molten pool area, and the increase of the temperature gradient is inevitable. This can cause thermal stress, resulting in the formation and propagation of cracks. In addition, $\mathrm{TiC}$ powder has a much higher absorption rate of laser energy than Co-based powder. Therefore, when a laser beam is applied to the powder of the preset layer, $\mathrm{TiC}$ has no time to precipitate and maintains the original morphology. This means that when the content of $\mathrm{TiC}$ is large, the TiC particles in the powder of the preset layer fail to decompose $\mathrm{Ti}$ and $\mathrm{C}$ atoms so that no in situ TiC occurs.

3.2. Microhardness of the Coatings. Figure 10 exhibits the microhardness distribution of cross section of S0, S1, S2, and S3 coatings. The coating hardness values are divided into 3 zones: HAZ, BZ, and CZ. The hardness values mostly improve greatly from the SUB zone to the HAZ, thereafter, reaching the highest value at the $\mathrm{CZ}$. The LC coating does not only create an extremely high hardness film but also enhances the hardness of the substrate by forming an HAZ with highly hardness value. This is because the quenching affection of the laser beam as the HAZ is heated and cooled down rapidly in the LC process [28]. Far away from the coating surface, this effect reduces its intensity as the thickness of the material increases [18]. The diffusion of the Co, Mo from the coating into the steel substrate, forming a strengthening solid solution, also contributes to the increase in the HAZ hardness [14]. The hardness numbers of the coatings are $499 \mathrm{HV}_{0.2}, 552 \mathrm{HV}_{0.2}, 590 \mathrm{HV}_{0.2}$, and $824 \mathrm{HV}_{0.2}$ corresponding to S0, S1, S2, and S3 coatings, respectively. The hardness number of the $\mathrm{CZ}$ increases gradually from the $\mathrm{S} 0$ to the S1, S2, and S3 as the TiC rate increases correspondingly. The hardness of the S0 coating is dramatically improved as comparing to the steel substrate. The appearance of the dendrites structure of the new $\mathrm{Cr}_{1.12} \mathrm{Ni}_{2.88}$ phase, as shown in Figure 4(a), which has high hardness value and

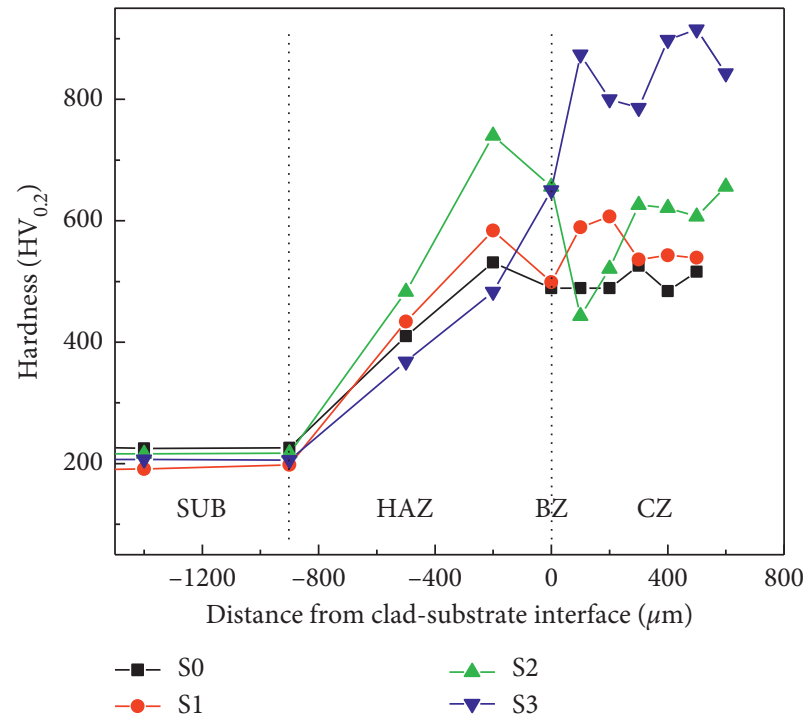

Figure 10: Microhardness distribution of cross section of S0, S1, S2, and S3 coatings.

well dispersion in the matrix is the reason of this improvement. This fine $\mathrm{Cr}_{1.12} \mathrm{Ni}_{2.88}$ phase also prevents the crystal growth in the material, therefore, constructing the fine grain microstructure. The presence of $\mathrm{TiC}$ particles in the S1, S2, and S3 coating powder leads to the formation of $\mathrm{TiCo}_{3}$ and $\mathrm{Cr}_{2} \mathrm{Ni}_{3}$ phases which have a high melting point and high hardness value. Moreover, the unmolten $\mathrm{TiC}$ particles and newly in situ TiC forming from the [Ti] and [C] atoms also contribute to the high hardness value of the coating [11], as shown in Figures 5, 8, and 9. Therefore, the higher the rate of $\mathrm{TiC}$ in the coatings, the higher the hardness number of the coatings due to the extreme high hardness of TiC. Comparing to the steel substrate or the SUB zone, the hardness values rise 2.4, 2.7, 2.8, and 4.0 times corresponding to S0, S1, S2, and S3 coatings, respectively. In conclusion, the hardness numbers of the surface are 


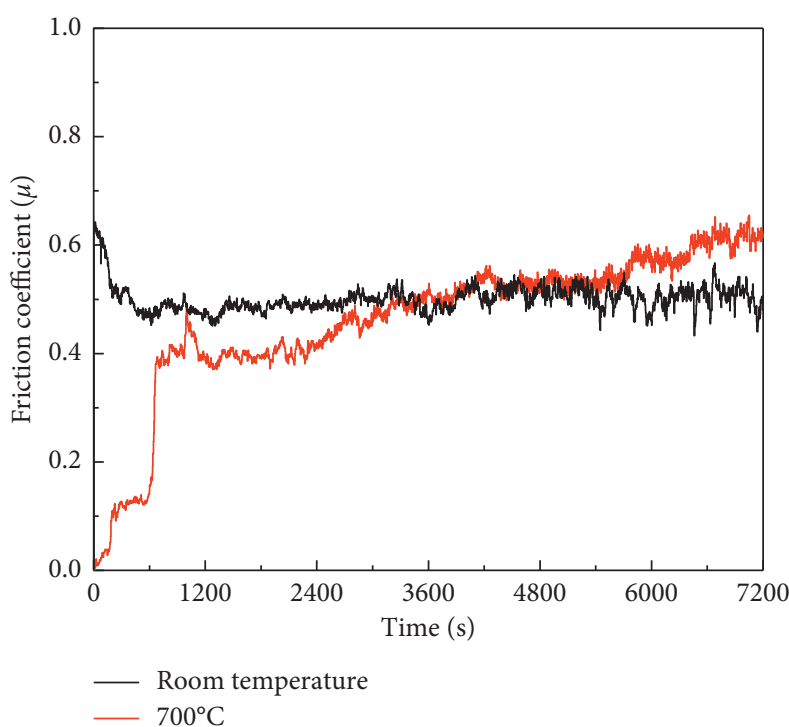

(a)

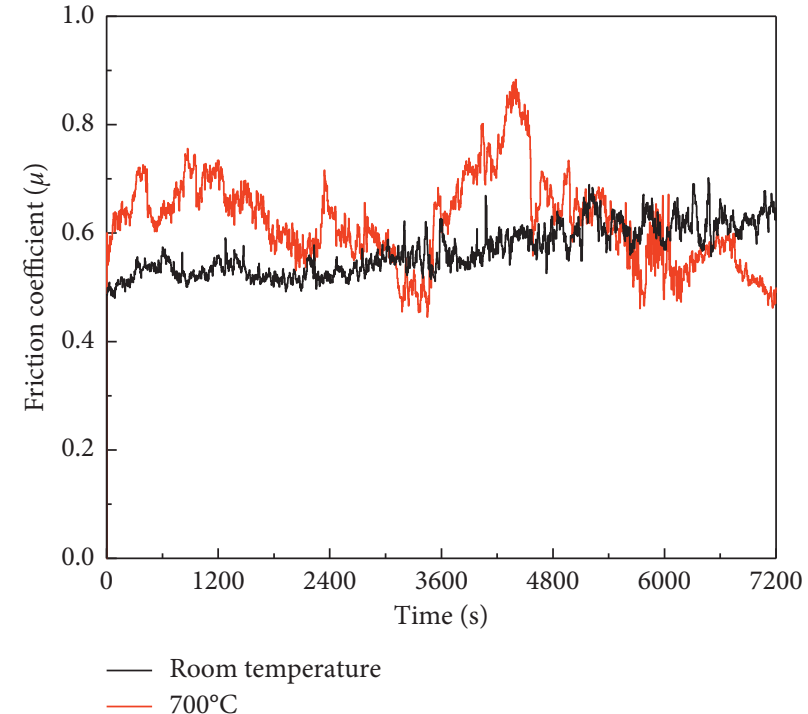

(b)

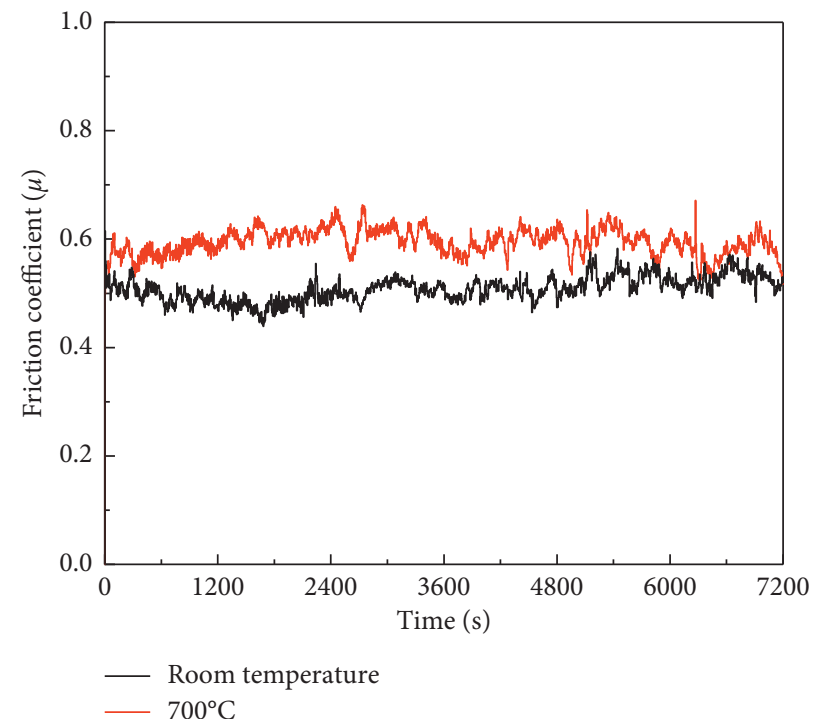

(c)

Figure 11: Friction coefficient vs. time curves of coatings at room temperature and $700^{\circ} \mathrm{C}$ : (a) S0 coating; (b) S1 coating; and (c) S2 coating.

significantly strengthened after coating and a higher portion of $\mathrm{TiC}$ creates a higher coating.

In the $\mathrm{CZ}$, the hardness numbers of the S1, S2, and S3 coatings experience a fluctuation. The diversity of TiC particle forms such as unmolten $\mathrm{TiC}$ particle, in situ TiC particle, and semimolten $\mathrm{TiC}$ particle creates an oscillation of the hardness value of them, as shown in Figures 4(a)-4(d). Thereafter, the hardness of these coating suffers a fluctuation.

Through the hardness number, we can predict the wear resistance of the coating. The higher hardness almost results in the higher wear resistance as the hardness is the measurement of the ability to resist the local deformation. Xu et al. [34] reported that, with WC powder, the hardness of the CZ could reach 600-800 HV50 depending on the rate of WC. The $\mathrm{WC}+\mathrm{Co}$-based coating has a lower hardness comparing to the $\mathrm{TiC}+\mathrm{Co}-$ based coating due to the fact that hardness of WC is lower than the hardness of $\mathrm{TiC}$. Comparing to $\mathrm{TiC}$ powder, adding $\mathrm{SiC}$ particle in Co-based coating could result in a higher value of the coating hardness that is up to 1300-1500 $\mathrm{HK}$ due to the higher hardness of the $\mathrm{SiC}$ [35]. Yang et al. [36] indicated that using TiCN powder leads to a high-value hardness of 703-774 HV, corresponding to $10-20 \%$ powder. Comparing to $\mathrm{S} 1$ and $\mathrm{S} 2$ samples, these hardness numbers are higher due to the higher hardness of TiCN. Implying a rich $\mathrm{Cr}$ powder mixing with Co-based alloy could gain a coating with $550 \mathrm{HV}$, which is much lower than the other types of coatings due to the lower hardness of chromium carbide [37].

3.3. Friction and Wear. Because S3 coating is not well combined with $\mathrm{H} 13$ substrate, the test of the friction and wear performance only selects S0, S1, and S2 samples. The 


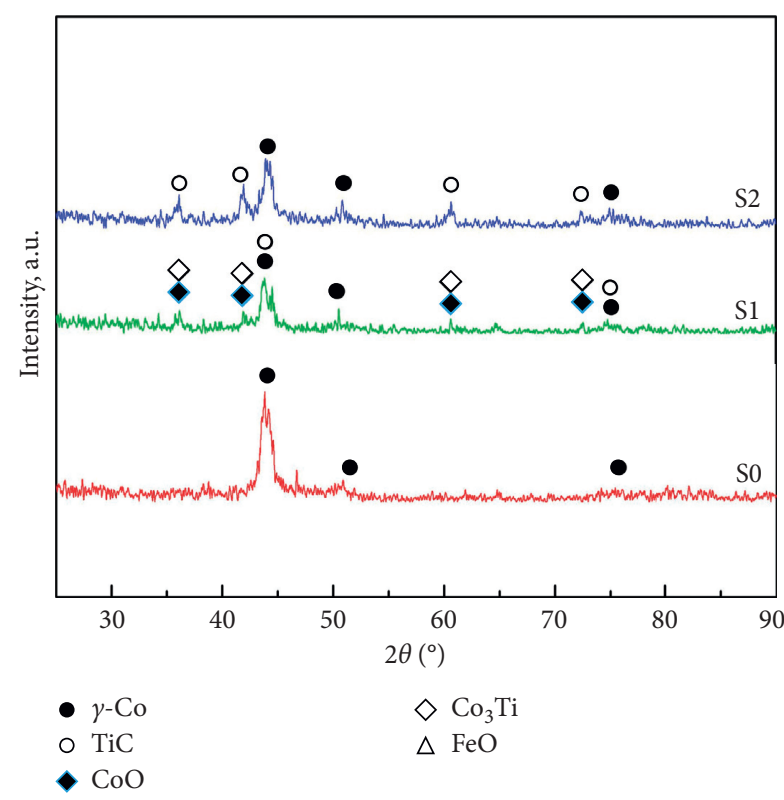

(a)

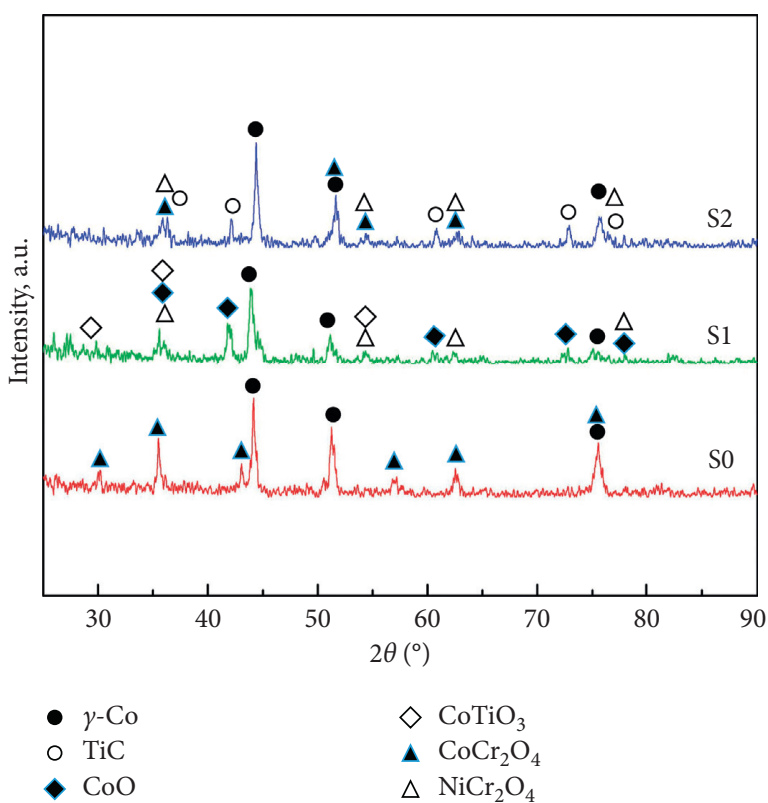

(b)

FIgURE 12: XRD patterns of S0, S1, and S2 coatings at (a) room temperature and (b) $700^{\circ} \mathrm{C}$.

maximum working temperature of hot work tool steel is $700^{\circ} \mathrm{C}$, so the maximum testing temperature is chosen as $700^{\circ} \mathrm{C}$.

Figure 11 demonstrates the friction coefficient of the S0, $\mathrm{S} 1$, and S2 samples at room temperature and $700^{\circ} \mathrm{C}$. At room temperature, the coefficient values of these coating samples slightly fluctuate around $0.5-0.6$. At $700^{\circ} \mathrm{C}$, the coefficient value of the S0 coating increase from 0 to 0.4 after 600 seconds due to the wear of the oxide layer, indicating the shift from the minor wear abrasion to a more severe wear state. The average coefficient value of the $S 1$ coating at $700^{\circ} \mathrm{C}$ strongly oscillated around 0.62 . The coefficient value of the S2 coating at $700^{\circ} \mathrm{C}$ is always stable around 0.6 . These results prove that the S0, S1, and S2 coatings have a great improvement on the wear resistance of $\mathrm{H} 13$ steel. The coating layer enhances the hardness of the surface, prevents it from being deformed or failure.

The results also show that the wear resistance of S2 coating is higher than S0. Because in the process of generating molten coatings, TiC particles are decomposed and recombined to form new $\mathrm{TiC}$ particles. These new $\mathrm{TiC}$ particles are strongly bonded to the matrix, having a very high hardness, and uniformly dispersed throughout the coating, thus, improving the wear resistance of the coating. Under the friction force, these enhanced $\mathrm{TiC}$ particles have a strong anti-deformation effect. The reasons are that they can resist the force and they play an important role in minimizing wear for the matrix. Moreover, during the decomposition process of $\mathrm{TiC}$ particles, they could combine with other molten elements to produce perinatal dendrite solid solution [29]. S2 coating is mainly composed of initially $\mathrm{TiC}$, in situ TiC, $\mathrm{Cr}_{2} \mathrm{Ni}_{3}$, and $\gamma$-Co solid solution. This solution is formed and spread evenly on the fine, small dendrite, and eutectic [30], therefore, increasing durability for cohesion between these microstructures and improving the durability and wear resistance of the coating. In addition, S2 sample does not appear plastic deformation; its wear mechanism is mainly adhesion type. In addition, the hardness of S2 is higher than S0, minimizing the surface deformation, thus, delaying the time of cracking formation as well as its development speed. These effects result in reducing the risk of cracks failure. The friction coefficient of S2 was stable with a quite high value. Candel et al. [32] show that when the laser beam's power density increases, the wear resistance is almost unchanged. Due to the influence on the concentration of $\mathrm{TiC}$, this contributes to the increase in the growth time of $\mathrm{TiC}$ in $\gamma$-Co, thereby forming a quite smooth friction surface. S2 coating has better antiwear performance as their TiC content is higher. When the S2 coating and the friction part are facing each other, as S2 is mainly composed of carbides, the friction parts are easily embedded in the softer $\gamma$-Co solid solution. In addition, during the ploughing process, friction parts encounter fewer obstacles; as a result, a deeper furrow is formed. Secondly, the hardness of S2 sample is higher than $\mathrm{S} 1$ one. In the wear process, increasing the coating hardness can reduce the deformation of the coating surface, decrease the propagation speed, postpone crack initiation time, and delay the chance of crack nucleation. However, the friction coefficient of the S2 coating is higher than S1. It may be due to the existence of hard phases in S2. Under high stress for a long time, the massive hard phase flakes and peels; thus, wear resistance is reduced [31].

Figure 12 exhibits the XRD diagrams of the coating after wear testing of S0, S1, and S2 coatings at room temperature and $700^{\circ} \mathrm{C}$. The results show that, in the $\mathrm{S} 1$ sample, $\mathrm{CoO}$ and $\mathrm{FeO}$ present in the room temperature testing. However, in 
the S0 and S2 coatings, they do not exist. At $700^{\circ} \mathrm{C}$, the $\mathrm{S} 0$ coating contents are $\mathrm{CoCr}_{2} \mathrm{O}_{4}$, while the $\mathrm{S} 1$ coating has $\mathrm{CoO}$, $\mathrm{CoTiO}_{3}$, and a small amount of $\mathrm{NiCr}_{2} \mathrm{O}_{4}$. The S2 sample possesses a great amount of $\mathrm{CoCr}_{2} \mathrm{O}_{4}$ and $\mathrm{NiCr}_{2} \mathrm{O}_{4}$ phases. Therefore, the existence of these oxides could influence the wear mechanism of the coating. At $700^{\circ} \mathrm{C}$, the wear mechanism of the S0, S1, and S2 coatings are mostly oxidation wear and fatigue wear. The reasons are the oxidation of the samples surface and the forming of the oxide layers. These oxide layers can protect the sample from wear. Nevertheless, they are brittle and can be cracked under the load, leading to fatigue spalling [33]. The oxidation and sloughing process take turns to each other during the wear process, therefore, improving the wear resistance at the hightemperature conditions.

\section{Conclusions}

(1) Co-based coating and TiC/Co-based composite coating were prepared on the surface of H13 mold steel by laser cladding. The coatings with a $\mathrm{TiC}$ percentage of less than $20 \%$ achieve a metal bonding type on the steel substrate. Applying the LC method could improve the hardness and wear resistance of the hot dies surface.

(2) Co50 alloy coatings are mainly composed of solid solutions $\gamma$-Co and $\mathrm{Cr}_{1.12} \mathrm{Ni}_{2.88}$. In $\mathrm{Co}+10 \% \mathrm{TiC}$ coating, there are $\mathrm{TiC}, \mathrm{TiCo}_{3}, \mathrm{Cr}_{2} \mathrm{Ni}_{3}$, and $\mathrm{Cr}-\mathrm{Ni}-\mathrm{Fe}-$ $\mathrm{C}$ phases. $\mathrm{Co}+20 \% \mathrm{TiC}$ composite coating consists of $\mathrm{TiC}, \mathrm{Cr}_{2} \mathrm{Ni}_{3}$, and $\gamma$-Co, while $\mathrm{Co}+30 \% \mathrm{TiC}$ coating consists mainly of $\mathrm{TiC}$ and $\gamma$-Co.

(3) $\mathrm{TiC}$ in the $\mathrm{TiC} / \mathrm{Co} 50$ composite coating is composed of two parts: incompletely melted $\mathrm{TiC}$ and in situ TiC. In situ $\mathrm{TiC}$ generated in the subsequent solidification process after the decomposition of TiC. TiC exists in different shapes: original TiC, fine particle $\mathrm{TiC}$, segregated $\mathrm{TiC}$, petal-shaped $\mathrm{TiC}$, and branchshaped $\mathrm{TiC}$. TiC size also gradually increases in the direction from the bonding zone to the surface layer.

(4) The TiC content has a great effect on the morphology of $\mathrm{TiC}$ in the composite coating, and the morphology of $\mathrm{TiC}$ in different areas of the coating is different. In $10 \% \mathrm{TiC}+\mathrm{Co} 50$ coating, $\mathrm{TiC}$ mainly appears as undermelted, fine particles, precipitates, and appears as polygons and petals. From the bottom of the coating, the number of TiC petals is increasing, and the particle size is increasing. In $20 \% \mathrm{TiC}+\mathrm{Co} 50$ coating, $\mathrm{TiC}$ in the coating mainly appears as undermelted, fine particles, and dendritic morphology. Moreover, from the bottom of this coating to the surface, the particle size of the undermelted $\mathrm{TiC}$ shows a clear gradient change. $30 \% \mathrm{TiC}+\mathrm{SCo} 50$ coating does not have in situ $\mathrm{TiC}$, and there is no obvious gradient change in the particle size of undermelted TiC.

(5) After being coated by the LC method with TiC/Co50 mixture, the surface hardness of the H13 steel is greatly improved. The hardness numbers of the coating are $499 \mathrm{HV}_{0.2}, 552 \mathrm{HV}_{0.2}, 590 \mathrm{HV}_{0.2}$, and 824 $\mathrm{HV}_{0.2}$, corresponding to Co50 coating, $10 \%$ $\mathrm{TiC}+\mathrm{Co} 50$ coating, 20\% TiC+Co50 coating, and 30\% $\mathrm{TiC}+\mathrm{Co} 50$ coating, respectively, which are 2.4-4.0 times higher than the $\mathrm{H} 13$ steel hardness. Adding $\mathrm{TiC}$ helps to increase the hardness of the coating to 53-325 $\mathrm{HV}_{0.2}$. The higher rate of $\mathrm{TiC}$, the higher the hardness of the coating. The coating of TiC/Co50 mixture significantly enhances the wear resistance of the $\mathrm{H} 13$ steel surface.

(6) The wear resistance of Co50 alloy, Co+10\% TiC, and $\mathrm{Co}+20 \% \mathrm{TiC}$ composite coatings is significantly higher than that of $\mathrm{H} 13$ steel, showing excellent wear characteristics. The friction coefficient of the coatings which have $\mathrm{TiC}$ is very stable. Therefore, the coatings can meet the demands of tool steels applications. Moreover, the wear mechanism of the coating at room temperature is mainly brittle spalling, adhesive, and ploughing. At $700^{\circ} \mathrm{C}$, the wear mechanism is mainly oxidation and fatigue. After coating by the LC method, the service life of the H13 tool steel will be greatly elongated. The research is very useful for the improvement of the wear resistance of the H13 steel.

\section{Data Availability}

The data used to support the findings of this study are available from the corresponding author upon request.

\section{Conflicts of Interest}

The authors declare that there are no conflicts of interest regarding the publication of this paper.

\section{Acknowledgments}

The authors acknowledge the Kunming University of Technology, HCMC University of Technology and Education, and Material Testing Laboratory (HCMUTE). They gave them an opportunity to join their team and granted them access to the laboratory and research machines. Without their appreciated support, it would not be possible to conduct this research.

\section{References}

[1] X. M. Liu, "Microstructure evolution of laser cladding with feeding powder for Co-based alloy in addition with WC in reheating and cooling process," Rare Metal Materials and Engineering, vol. 36, no. 4, pp. 621-624, 2007.

[2] A. Emamian, S. F. Corbin, and A. Khajepour, "Tribology characteristics of in-situ laser deposition of Fe-TiC," Surface and Coatings Technology, vol. 206, no. 22, pp. 4495-4501, 2012.

[3] M. X. Li, Y. Z. He, and G. X. Sun, "Microstructure of wide/ narrow band beam laser cladding Co-based alloy on $\mathrm{Ni}$ base superalloy/45\# steel," Chinese Journal of Lasers, vol. 30, no. 11, pp. 1044-1048, 2003.

[4] M. X. Li, Y. Z. He, and G. X. Sun, "Microstructure and crystallization direction of laser cladding Co-based alloy," 
Journal of Southeast University (Natural Science Edition), vol. 32, no. 6, pp. 1-4, 2002.

[5] Y. T. Pei, Q. C. Meng, and J. H. Ouyang, "Dissolution and precipitation of $\mathrm{TiC}$ particles and their distribution in a laser clad 30 vol. \% $\mathrm{TiC}_{\mathrm{p}} / \mathrm{Ni}$-alloy composite coating," Chinese Journal of Lasers, vol. 22, no. 12, pp. 935-938, 1995.

[6] Y. T. Pei, "Laser clad $\mathrm{TiC}_{\mathrm{p}} / \mathrm{Ni}$ alloy functionally gradient coating and its in-situ formation mechanism," Acta Metallurgica Sinica, vol. 34, no. 9, pp. 987-991, 1998.

[7] A. E. Karantzalis, A. Lekatou, and K. Tsirka, "Solidification observations and sliding wear behavior of vacuum arc melting processed Ni-Al-TiC composites," Materials Characterization, vol. 69, pp. 97-107, 2012.

[8] J. B. Zhang, The Research on Mechanical Surface Treatment and Laser Alloying of Titanium, Graduate Lanzhou University of Technology, Lanzhou, China, 2007.

[9] Y. Chen and H. M. Wang, "Eutectic MC carbide growth morphologies of a laser clad $\mathrm{TiC} / \mathrm{FeAl}$ composite coating," Materials Letters, vol. 59, no. 28, pp. 3699-3702, 2005.

[10] D. Fan, J. J. Dai, and Y. N. Sun, "Microstructure and property of TiC/Ti composite coating by laser surface alloying," Journal of Lanzhou University of Technology, vol. 32, no. 4, pp. 13-15, 2006.

[11] C. Q. Li and S. K. Chen, "Research on properties of Ni/TiC on 45 steel surface prepared by laser cladding," Equipment Manufacturing Technology, vol. 8, pp. 20-22, 2011.

[12] L. Liu, J. Niu, and Y. Tian, "Study of interface reaction and effecting factor of aluminium matrix composite under laser welding condition," Journal of Materials Engineering, vol. 3, pp. 38-44, 1999.

[13] C. Cui, Z. Guo, H. Wang, and J. Hu, "In situ TiC particles reinforced grey cast iron composite fabricated by laser cladding of Ni-Ti-C system," Journal of Materials Processing Technology, vol. 183, no. 2-3, pp. 380-385, 2007.

[14] C. Zhang, "Study on microstructure of laser cladding Co-base alloy on nuclear valve parts," Laser Technology, vol. 25, no. 2, pp. 129-133, 2001.

[15] Y. Xiong, Y. Wang, and K. F. Zhang, "Microstructure and properties of laser cladding Stellite6/WC," China Surface Engineering, vol. 30, no. 3, pp. 220-223, 2001.

[16] S. H. Si, K. Xu, and Y. L. Liu, "Microstructure and performance of laser cladding $\mathrm{Co}+\mathrm{Cr}_{3} \mathrm{C}_{2}$ composite coating," Transactions of the China Welding Institution, vol. 27, no. 4, pp. 45-48, 2006.

[17] S. H. Si, K. Xu, and X. M. Yuan, "Microstructure and wear performance of laser classing $\mathrm{Cr}_{3} \mathrm{C}_{2} / \mathrm{Co}$ alloy composite coating," Tribology, vol. 26, no. 2, pp. 125-129, 2006.

[18] S. H. Si, Y. Z. H. He, and X. M. Yuan, "Microstructure and wear-resistance of laser clad Co-based alloy coatings with $\mathrm{B}_{4} \mathrm{C}_{\mathrm{p}}$ and $\mathrm{SiC}_{\mathrm{p}}$," The Chinese Journal of Nonferrous Metals, vol. 13, no. 2, pp. 454-459, 2003.

[19] W. R. Morrow, H. Qi, I. Kim, J. Mazumder, and S. J. Skerlos, "Environmental aspects of laser-based and conventional tool and die manufacturing," Journal of Cleaner Production, vol. 15, no. 10, pp. 932-943, 2007.

[20] S. Zhang, C. H. H. Zhang, and H. C. Man, "Microstructure and performance of a laser clad Co-based alloy on 2Cr13 stainless," Rare Metal Materials and Engineering, vol. 30, no. 3, pp. 220-223, 2001.

[21] Y. Herrera, I. C. Grigorescu, J. Ramirez, C. Di Rauso, and M. H. Staia, "Microstructural characterization of vanadium carbide laser clad coatings," Surface and Coatings Technology, vol. 108-109, no. 10, pp. 308-311, 1998.
[22] Z. Huang, Q. Cai, and J. Niu, "Research progress of iron and steel material strengthened by particle," Material \& Heat Treatment, vol. 40, no. 8, pp. 79-83, 2011.

[23] C. Peng and M. Zhang, "Influence of preparative conditions on the size and morphology of nano-Co particles," Journal of Anhui University of Science and Technology (Natural Science), vol. 28, no. 3, pp. 57-60, 2008.

[24] H. Zhao, L. Zhu, and X. Ma, "New techniques of preparing nano structured tungsten carbides," Journal of Materials Science \& Engineering, vol. 21, no. 1, pp. 130-133, 2003.

[25] M. Zhao, M. Guo, and J. Feng, "Preparation methods of particle reinforced surface metal matrix composites," Transactions of the China Welding Institution, vol. 28, no. 2, pp. 108-112, 2007.

[26] A. E. Karantzalis, A. Lekatou, E. Georgatis, Z. Arni, and V. Dracopoulos, "Solidification observations of vacuum arc melting processed Fe-Al-TiC composites: TiC precipitation mechanisms," Materials Characterization, vol. 62, no. 12, pp. 1196-1204, 2011.

[27] H. Li, H. Zhao, and W. Wang, "Microstructure of an in-situ synthesized TiC wearing coating by laser cladding," Aviation Precision Manufacturing Technology, vol. 46, no. 2, pp. 37-40, 2010.

[28] X. Y. Qian, H. Q. Tong, and D. L. Zhang, "Microstructure and performance of laser-cladding Co-based alloy coating on the surface of H13 mold steel," Metallurgical Collections, vol. 5, pp. 1-3, 2011.

[29] Y. M. Zhao, J. L. Wang, and J. W. Mou, "Microstructures and properties of Co-based alloy coatings prepared on surface of H13 steel," China Welding, vol. 19, no. 3, pp. 41-44, 2010.

[30] Y. Si-You, J.-Y. Liu, and W. Yang, "Quality of H13 alloy coating on H13 steel prepared by laser cladding," Surface Technology, vol. 8, no. 44, pp. 81-87, 2015.

[31] J. S. Guo, J. W. Su, and C. S. Guang, "Research on impact wear resistance of in situ reaction TiCp/Fe composite," Wear, vol. 269, no. 3-4, pp. 285-290, 2010.

[32] J. J. Candel, V. Amigó, J. A. Ramos, and D. Busquets, "Sliding wear resistance of TiCp reinforced titanium composite coating produced by laser cladding," Surface and Coatings Technology, vol. 204, no. 20, pp. 3161-3166, 2010.

[33] H. Kashani, A. Amadeh, and H. M. Ghasemi, "Room and high temperature wear behaviors of nickel and cobalt base weld overlay coatings on hot forging dies," Wear, vol. 262, no. 7-8, pp. 800-806, 2007.

[34] G. Xu, M. Kutsuna, Z. Liu, and L. Sun, "Characteristic behaviours of clad layer by a multi-layer laser cladding with powder mixture of stellite- 6 and tungsten carbide," Surface and Coatings Technology, vol. 201, no. 6, pp. 3385-3392, 2006.

[35] W. P. Zhang, Z. H. Lang, and H. B. Ma, "Microstructure and performance of laser cladding $\mathrm{SiC} / \mathrm{Co}$ coating," Surface Technology, vol. 40, no. 1, pp. 8-10, 2011.

[36] Y. L. Yang, D. Y. Dong, Z. Yang, B. K. Zhang, and N. Guo, "Microstructure and wear resistance of TiCN-reinforced Co matrix coatings on tool steel," Materials Science and Technology, vol. 32, no. 4, pp. 291-298, 2016.

[37] N. Jeyaprakash, C.-H. Yang, and S. Sivasankaran, "Laser cladding process of cobalt and nickel based hard-micronlayers on 316L-stainless-steel-substrate," Materials and Manufacturing Processes, vol. 35, no. 2, pp. 142-151, 2020. 